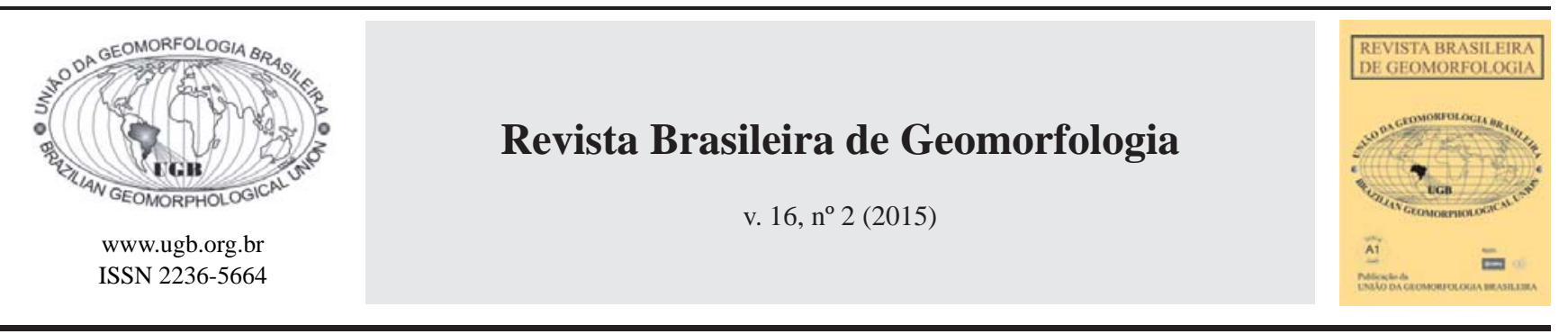

\title{
BARREIRAS COSTEIRAS HOLOCÊNICAS: GEOMORFOLOGIA E ARQUITETURA DEPOSICIONAL NO LITORAL DO RIO DE JANEIRO
}

\author{
HOLOCENE COASTAL BARRIERS: GEOMORPHOLOGY AND \\ DEPOSITIONAL ARCHITECTURE ON THE RIO DE JANEIRO COAST
}

\author{
Guilherme Borges Fernandez \\ Departamento de Geografia, Universidade Federal Fluminense
} Av. General Milton Tavares de Souza, s/nº, Niterói, Rio de Janeiro, CEP: 24210-346, Brasil

E-mail: guilhermefernandez@id.uff.br

Thaís Baptista da Rocha

Departamento de Geografia Física, Universidade do Estado do Rio de Janeiro Rua São Francisco Xavier, 524, Rio de Janeiro, Rio de Janeiro, CEP: 20550-01, Brasil

E-mail: thaisitc5@yahoo.com.br

\begin{tabular}{l} 
Informações sobre o Artigo \\
\hline Data de Recebimento: \\
05/10/2014 \\
Data de Aprovação: \\
09/04/2015
\end{tabular}

Palavras-chave:

Geomorfologia Costeira; Radar de Penetração do Solo; Nível

Médio do Mar

\section{Keywords:}

Coastal Geomorphology;

Ground Penetrating Radar; Sea Level Mean

\section{Resumo:}

O presente trabalho tem como objetivo caracterizar diferentes morfologias e arquiteturas deposicionais das barreiras costeiras holocênicas, no litoral do Rio de Janeiro. O trabalho se concentrou em trechos do litoral centro-norte do Rio de Janeiro, abarcando a planície do Peró em Cabo Frio, o litoral de Quissamã e a planície deltaica do rio Paraíba do Sul, em Gargaú. Foram utilizados dados morfológicos e morfodinâmicos a partir de levantamentos topográficos transversais à praia, e também por mapeamento em planta em escala de detalhe e regional. A arquitetura deposicional foi obtida com sistema GPR em modo Common-Offset, com antena de 400 Mhz. Em Gargaú, a morfologia de cristas de praia reflete a migração do ambiente praial sobre a antepraia, compondo uma planície costeira regressiva, associado ao aporte fluvial do rio Paraíba do Sul. Foi estimada uma progradação de aproximadamente 12 m/ano. Em Quissamã, a morfologia da barreira truncando lagunas costeiras evidencia a composição transgressiva, também expressa nas radarfácies de leques de transposição, depósito lagunar e esporão. Estes corpos lagunares têm sido associados ao máximo transgressivo holocênico, entre 6.000 à 5.000 anos A.P. Esta área não recebe aporte sedimentar moderno do rio Paraíba do Sul sendo, provavelmente, um fator para as condições transgressivas da barreira. O monitoramento da linha de costa tem indicado um recuo da escarpa erosiva em torno de $1 \mathrm{~m} / \mathrm{ano}$. A tipologia de barreira agradacional foi identificada na praia do Peró, caracterizada pelo desenvolvimento de dunas frontais sobre substrato praial ou lagunar. A arquitetura interna apresenta radarfácies eólicas associadas a um transporte de ventos do mar para terra e fixadas pela vegetação. O estado intermediário/dissipativo da praia também é um elemento importante para o desenvolvimento das dunas frontais e o consequente empilhamento vertical da barreira. O comportamento da linha de 
costa é estável e a barreira apresenta boa resiliência para recuperação frente aos eventos de tempestade. Conclui-se que, mesmo com a diminuição relativa do nível do mar durante o Holoceno Tardio, as barreiras não apresentam características exclusivas referentes à tipologia de barreira regressiva. Outros fatores influenciam a morfologia e a arquitetura deposicional das barreiras costeiras ao longo do litoral do Rio de Janeiro, tais como o aporte sedimentar, a exposição a eventos de tempestade, a morfodinâmica de praia e potencial eólico.

\section{Abstract:}

The aim of this study is to characterize different morphologies and depositional architectures of the Holocene coastal barriers, in the Rio de Janeiro coast. This work concentrated in part of the Rio de Janeiro state, covering the Peró plain in Cabo Frio, the Quissamã plain and deltaic plain of Paraíba do Sul River, in Gargaú. Morphological and morphodynamic data were used, originating from beach profiles and mapping in plant with detail and regional scales. The depositional architecture was obtained with GPR system in Common-offset mode, with specific setup for $400 \mathrm{MHz}$ antenna. In Gargaú, the beach ridges morphology reflects the migration of the beach environment on the shoreface, composing a regressive coastal plain, associated with fluvial input from the Paraíba do Sul river. Estimated progradation rate was found to be around $12 \mathrm{~m}$ / year. In Quissamã, the barrier truncates coastal lagoons due to translational behavior, forming radar sequences of washover fans and radarfacies oriented onshore deposits, above lagoon material. These lagoons bodies have been associated to the Holocene sea level high stand between 5.000 and 6.000 yrs BP. This area does not receive modern sediments from Paraíba do Sul river, probably this causes the transgressive condition. The monitoring of the shoreline has indicated a retreat of erosive scarp around $1 \mathrm{~m} /$ year. The aggradational pattern was identified in Peró beach, characterized by develop of foredunes above beach/lagoon deposits. The depositional structure suggests trends of aeolian sequences associated with onshore sediment transport, fixed by vegetation. The intermediate/dissipative morphodynamic state of beach is an important element for the development of foredunes and the vertical accretion of the barrier. The shoreline behavior is stable and the barrier has good resilience to recover from storm events. We conclude that even with the Holocene relative sea-level lowering observed along Rio de Janeiro coast barriers don't exclusively show regressive characteristics. Other factors influence the morphological and internal sedimentary architecture, such sediment input, exposure to storm events, morphodynamic state of beach and wind.

\section{Introdução}

Grande parte do litoral brasileiro encaixa-se na tipologia de "costas dominadas por ondas”. Segundo Davis e Hayes (1984) estas costas são caracterizadas como aquelas onde a ação de ondas gera significativo transporte sedimentar, que predominam sob a forçante de maré, sendo normalmente associada a ambientes de micromaré. Desta forma, nestas costas normalmente se desenvolvem extensas feições deposicionais arenosas, também conhecidas como Barreiras Costeiras (coastal sandy barriers). Segundo Otvos (2012) essas feições representam $15 \%$ do total das linhas de costa do mundo, podendo apresentar como sub-ambientes deposicionais as praias, dunas frontais, planícies de deflação, brejos, canais de maré, leques de transposição e lagunas.

Otvos (2012) ressalta que o termo barreira costeira possui definições e interpretações variadas. Inicialmente foi considerado como depósito arenoso paralelo à linha de costa, parcialmente conectado ao continente (spits) ou totalmente desconectado (ilha barreira). Recentemente, o autor sistematizou uma terceira categoria que inclui as planícies costeiras associadas a cristas de praia e campos de dunas transgressivos. Enquanto spits e ilhas-barreiras estão originalmente atreladas ao contexto do litoral norte-americano, a terceira categoria tem sido amplamente desenvolvida nas costas da Austrália e do Brasil.

De acordo com Dillenburg e Hesp (2009), são encontradas formas distintas de barreiras, em função, por exemplo, da presença ou não de dunas, da conexão ou individualização com o continente, das características estratigráficas e do comportamento da barreira em relação à linha de costa, isto é, podendo migrar em direção ao continente ou em direção ao mar. Em relação a estes últimos, o comportamento do nível do mar e o balanço sedimentar são os principais fatores de controle para evolução de barreiras costeiras, onde estas podem apresentar comportamento regressivo, transgressivo ou 
agradacional (OTVOS, 2012; DILLENBURG e HESP, 2009; ROY et al.,1994; NIEDORODA et al., 1985; KRAFT E JOHN, 1979).

Provavelmente os primeiros trabalhos que sintetizaram os aspectos morfológicos e de arquitetura deposicional das barreiras costeiras em diversas condições de flutuações no nível do mar, foram feitos por Kraft e Jonh (1979) e Galloway e Hobday (1983). Numa situação transgressiva haveria tendência de migração da feição em direção ao continente a partir de leques de transposição, determinando morfologicamente a formação de sistemas barreira laguna. A arquitetura deposicional se configuraria com sedimentos lagunares posicionados na base da barreira e sedimentos praias no topo (Figura 1).

Por outro lado, em sequências associadas à regressão marinha, a arquitetura deposicional mostraria na base sedimentos que normalmente estão depositados nas partes mais distais do prisma praial, em resposta à progradação (Figura 1). Morfologicamente esta arquitetura poderia estar associada a cristas de praias. Galloway e Hobday (1983) apresentam ainda a possibilidade de formação de sequencias agradacionais, isto é, com projeção sedimentar vertical das barreiras por incorporação de sedimentos eólicos (Figura 1).

Roy et al. (1994), a partir de exemplos da costa australiana, identificaram uma série de possibilidades morfológicas e na arquitetura deposicional, apresentando diferentes condições de flutuações no nível do mar, ou seja, padrões associados a feições regressivas e transgressivas, e ainda um complexo quadro de diferentes feições, formadas em condições quase estáveis do nível do mar. Os autores enfatizaram que nestas condições podem ocorrer feições progradantes, barreiras transgressivas associadas a formação de dunas que migrariam em direção ao continente, além de barreiras estacionárias, indicando agradação vertical.

Estudos que revisaram de forma ampla a formação e dinâmica de barreiras costeiras foram recentemente publicados por McBride et al. (2013) e VanHeteren (2014) O primeiro, aponta que estudos futuros sobre estes ambientes, devam integrar diferentes métodos que avaliem a parte referente a subsuperfície e superfície, além da atenção especial ao comportamento futuro destas feições, em relação a sua evolução morfológica. Mais recentemente Van Heteren (2014) apresenta diversas possibilidades de interpretação morfológica das barreiras costeiras, enfatizando não somente o comportamento associado a migração transgressiva, regressiva ou agradacional, mas também mostrando as possibilidades de diferenças na fisiografia, associadas a distribuição em planta assumidas por distintos processos controladores.

Na costa brasileira, Dillenburg e Hesp (2009) organizaram um compêndio sobre as barreiras costeiras holocênicas. Especificamente no litoral do Rio de Janeiro, foram sintetizadas as principais características das barreiras e a evolução Quaternária das respectivas planícies (ver DIAS e KJERFVE, 2009). Porém, apesar da contribuição, o trabalho demonstrou a carência de informações cronológicas e de subsuperfície referente ao litoral fluminense, sobretudo em relação ao método GPR. Este tem sido considerado um dos principais métodos de investigação referente a estas feições, conforme tem mostrado Silva et al. (2014), Rocha et al. (2013a), Barboza et al. (2011), Costas e FitzGerald (2011), Dillenburg et al. (2011), Girardi e Davis (2010), Barboza et al. (2009), Bennett et al. (2008), Wang e Horwitz (2007), Caldas et al. (2006). Nesse sentido, o presente trabalho tem como objetivo caracterizar as diferenças morfológicas e distintos arranjos na arquitetura deposicional das barreiras costeiras holocênicas, observadas no litoral do Rio de Janeiro, considerando aspectos de comportamento do nível do mar, morfodinâmica de praia e geomorfologia de detalhe.

\section{Área de estudo}

O litoral do Rio de Janeiro é marcado por planícies costeiras francamente dominadas por ação das ondas e associadas às flutuações no nível do mar, formadas por terraços pleistocênicos e holocênicos conforme sugerido por Muehe e Valentini (1998) e Rocha et al. (2013a). De forma geral as barreiras holocênicas estão formadas frontalmente ao mar e separadas por alguma outra feição como lagoas costeiras ou planícies lagunares e de deflação (Dias e Kjerve, 2009). Para este trabalho foram selecionados trechos do litoral centro-norte do Rio de Janeiro como a planície costeira do Peró, e duas áreas do Complexo Deltaico do Rio Paraíba do Sul. Este último pode ser dividido entre a área de influência direta da sedimentação fluvial, localizada desde as proximidades da localidade de Gargaú e o Cabo de São Tomé; e o trecho abandonado do delta, nas proximidades da cidade de Quissamã (Figura 2).

De acordo com Muehe e Valentini (1998) este 

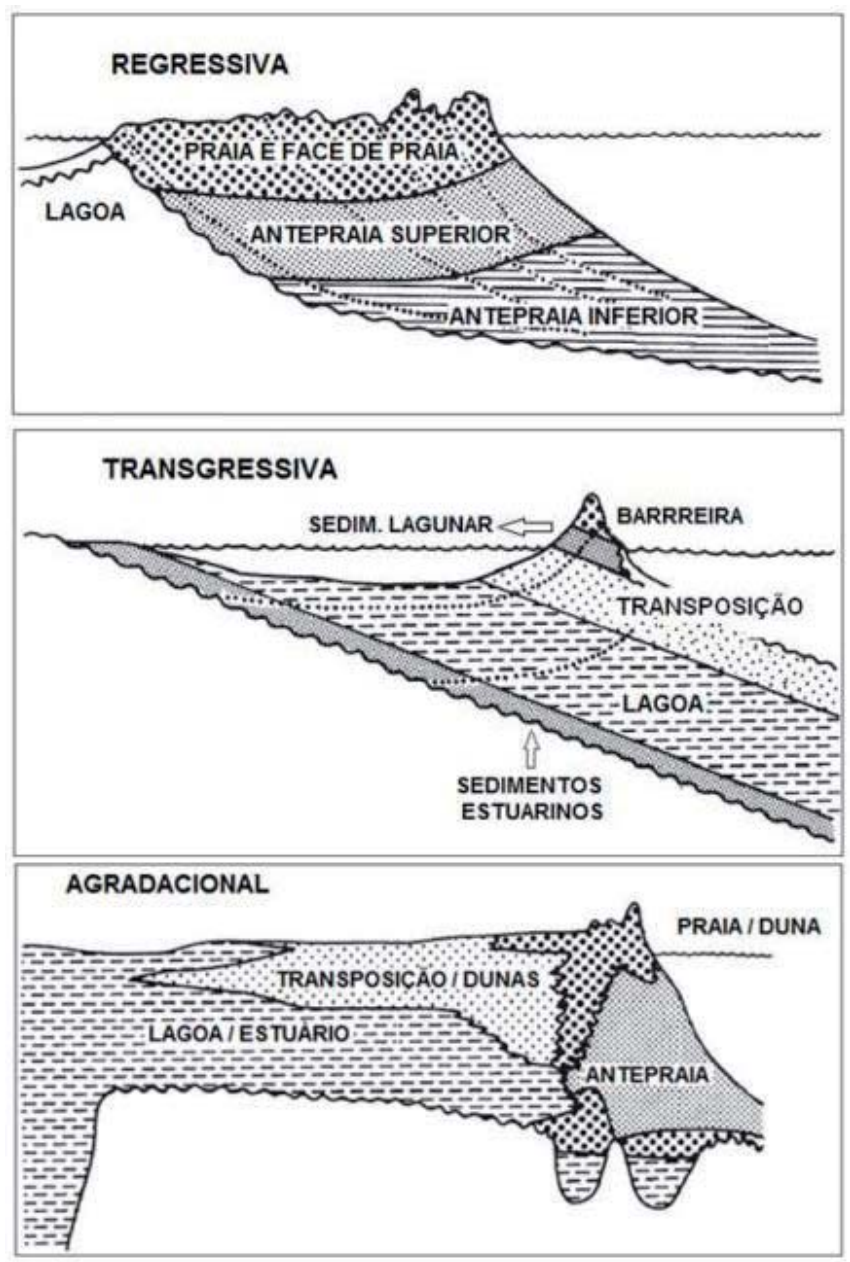

Figura 1 - Modelo estratigráfico de barreira regressiva, transgressiva e agradacional (Modificado de KRAFT e JOHN, 1979 e GALLOWAY e HOBDAY, 1983).

setor do liroral centro-norte faz parte do Macro-compartimento de Campos, cuja orientação do litoral é predominante nordeste-sudoeste, condicionada pela direção geológico-estrutural imposta pelo ciclo brasiliano, típica do litoral brasileiro entre o cabo Calcanhar, no Rio Grande do Norte, e o Rio Grande do Sul. Cabe ressaltar que o litoral referente ao delta do Paraíba do Sul apresenta uma orientação quase norte-sul, em função da progradação desenvolvida durante o Holoceno Tardio.

As condições oceanográficas e meteorológicas estão associadas à célula de alta pressão semi-fixa que domina grande parte da costa leste brasileira, responsável pelas ondas de tempo bom, e aos sistemas frontais, responsáveis pelas ondas de tempestade. As primeiras são as ondas mais representativas, com período entre 6 e 7 segundos, altura significativa entre 1,5 e $2 \mathrm{~m}$, oriundas do quadrante NE. Nas condições de tempestade as ondas possuem período entre 8 e 16 segundos, altura entre 2,5 e 4,5 metros e direções S, SW e SE (PINHO, 2003). A padrão de marés é semi-diurno, alcançando até 1,3 metros na maré alta de sizígia e 0,3 metros na maré baixa configurando, portanto, amplitude de micro-maré, o que ressalta a tipologia de costa dominada por ondas.

Em termos de comportamento do nível do mar no Holoceno, a costa fluminense apresenta as mesmas características estabelecidas na maior parte do litoral brasileiro. Segundo Angulo et al. (2006), a mar teria atingido o nível máximo entre 5.000 e 5.800 anos A.P., podendo ter alcançado até aproximadamente 4,5 metros acima do nível médio atual, com valores mínimos de 2,5 metros, dentro da variação apresentada pelas datações utilizadas. Apesar do comportamento de diminuição do nível do mar entre o máximo transgressivo e o presente, tal tendência não foi suficiente para que se formassem a priori feições associadas às características morfológicas regressivas. Neste sentido as barreiras costeiras no estado do Rio apresentam características que vão além do padrão geral de oscilação do nível do mar, envolvendo uma série de fatores que podem ser identificados em parte pela morfologia e arquitetura deposicional.

\section{Materiais e métodos}

Foram utilizados métodos para aquisição de dados em superfície e subsuperfície. Em superfície, os dados morfológicos e morfodinâmicos foram obtidos a partir de perfis topográficos transversais à praia, estabelecidos com Estação Total e corrigidos pelo nível médio do mar (Figura 2). O monitoramento destes perfis faz parte de um banco de dados de monitoramento de morfodinâmica de praias, alguns iniciados no ano de 2005 (FERNANDEZ et al. 2012). Também foram realizados mapeamentos em planta da geomorfologia na escala de detalhe (1:25.000) para as planícies do Peró e Quissamã a partir de ortofotos do ano 2005, e em escala regional para a planície do delta do Paraiba do Sul (1:400.000), adaptado da fonte CPRM.

Para o levantamento da arquitetura deposicional foi utilizado um sistema GPR (Radar de Penetração do Solo) modelo SIR 3000, com antena de $400 \mathrm{MHz}$, cujo levantamento foi realizado no modo common-offset, que consiste numa única antena de transmissão e recepção (Figura 2 e 3). O GPR detecta descontinuidades elétricas de materiais que estão em subsuperfície, através da geração, transmissão, propagação, refração e recepção 


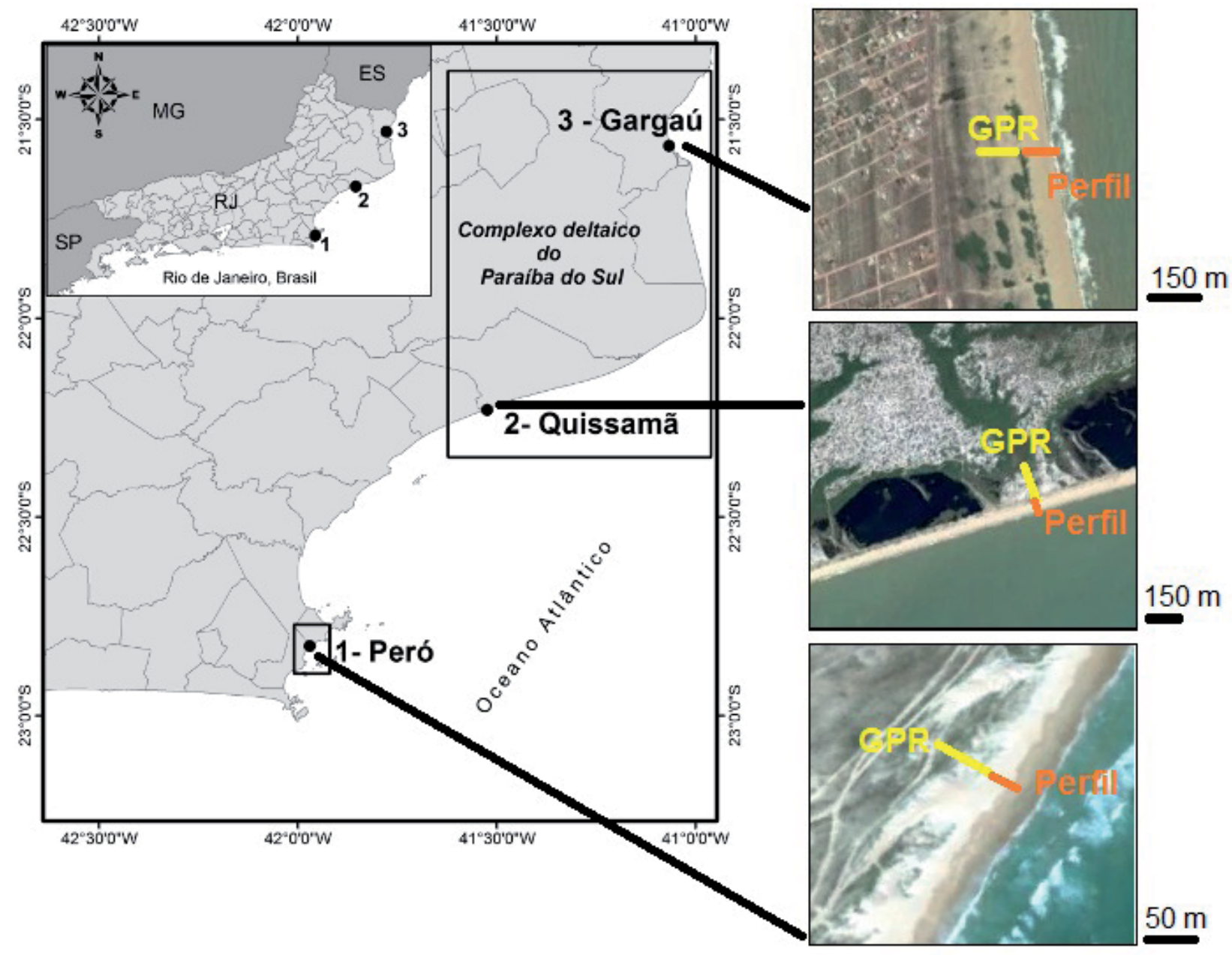

Figura 2 - Localização da área de estudo. Em destaque está a localização das linhas de GPR (em amarelo) e dos perfis topográficos transversais à praia (em laranja).

de pulsos discretos de alta frequência eletromagnética. A velocidade de propagação da onda e a reflexão do sinal são alteradas na medida em que as camadas deposicionais vão apresentando mudanças no conteúdo de água, na porosidade, na granulometria, no tipo de sedimento e na orientação dos acamamentos, refletindo em mudanças nas propriedades elétricas. Consequentemente, o lençol freático, as estruturas sedimentares e os contatos litológicos tendem a ser bem visíveis no GPR, o que torna o método uma poderosa ferramenta de investigação e análise aplicada à sedimentologia (Neal, 2004).

Para a conversão do tempo (ns) em profundidade (m) foi utilizado um diagrama de velocidade obtido a partir de uma seção GPR em modo Common- MidPoint (CMP), com antenas de $80 \mathrm{Mhz}$. A velocidade variou entre 0,15 até $0,06 \mathrm{~m} / \mathrm{ns}$, considerada coerente para sedimentos arenosos segundo Nilsen et al. (2009). Em gabinete, os dados foram processados no softwa- re RADAN 6.6, cujas técnicas estão relacionadas ao processamento sísmico. Primeiramente realizou-se a correção topográfica, cujos dados foram obtidos com estação total, conforme mencionado anteriormente. Em seguida foi utilizado filtro passa-banda e ganho, uma vez que o sinal geofísico tende a ser progressivamente atenuado; aplicação de filtros espaciais e migração para remoção de ruídos e difrações.

O perfil pós-processado foi interpretado e redesenhado no software CorelDRAW X5. A interpretação das radarfácies foi feita considerando inconformidades, morfologia, mergulho e continuidade dos refletores conforme sugerido por Neal (2004). A legenda das radarfácies foi baseada primeiramente no tipo de ambiente deposicional, seguido das especificidades da arquitetura deposicional. Por exemplo, a radarfácie f6c possui característica eólica, com arquitetura de estratificação cruzada. A legenda completa das radarfácies encontra-se na figura 4. 


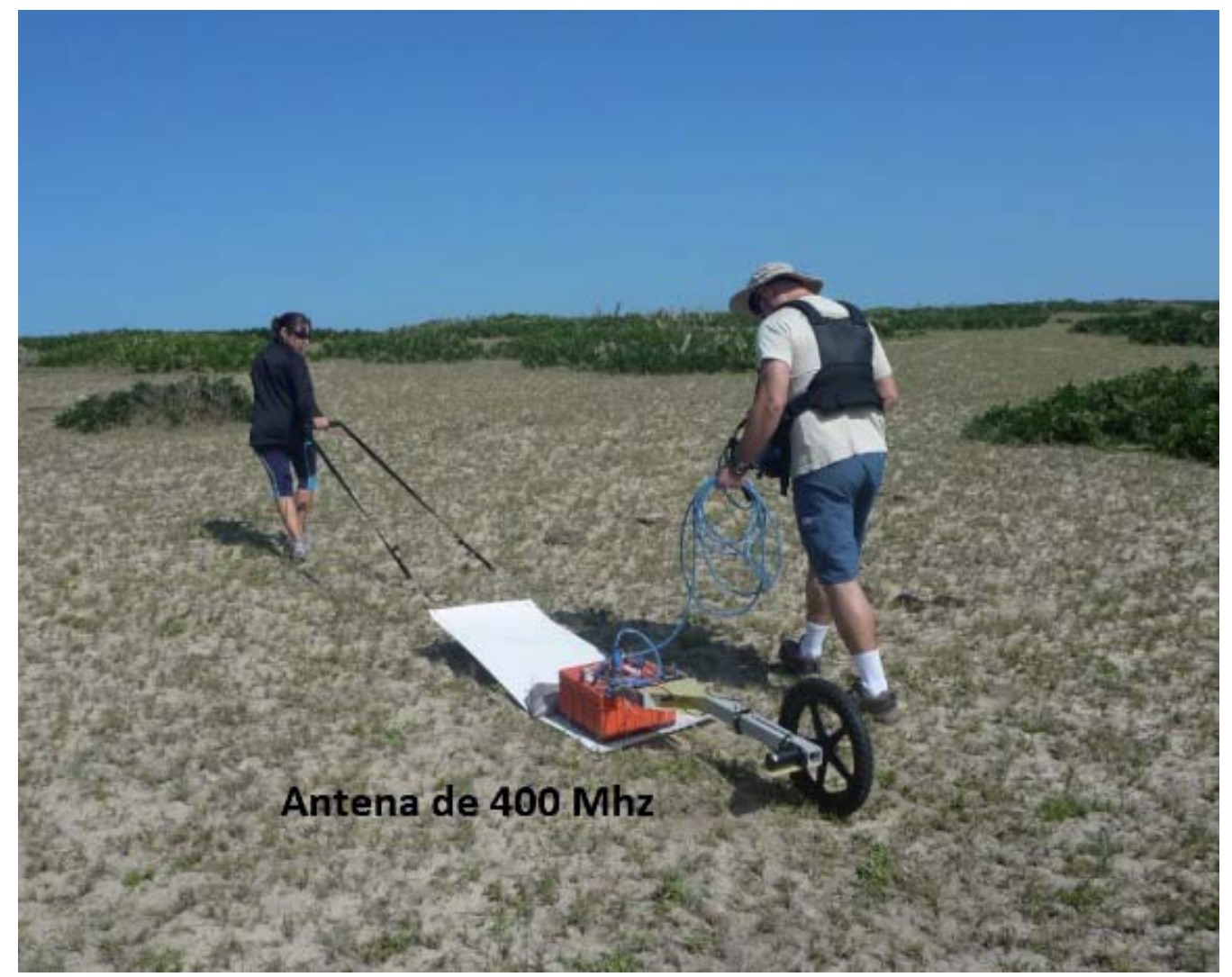

Figura 3 - Seção GPR em modo common-offset,com antena de 400 Mhz.

\begin{tabular}{|c|c|c|c|c|c|}
\hline \multirow{2}{*}{\multicolumn{2}{|c|}{${ }_{-1}^{E}$}} & \multirow[t]{2}{*}{$\begin{array}{l}\text { Pós-praia } \\
\text { f1a- Pós-praia e } \\
\text { zona de estirâncio }\end{array}$} & \multirow[t]{2}{*}{$\begin{array}{c}E \\
\stackrel{5}{-}\end{array}$} & $20 \mathrm{~m}$ & f4 - Depósito lagunar \\
\hline & & & & & Eólico \\
\hline $\begin{array}{c}E \\
5 \\
L\end{array}$ & & $\begin{array}{l}\text { f1b- Agradação de } \\
\text { berma }\end{array}$ & $\stackrel{E}{E}$ & $5,0 \mathrm{~m}$ & $\begin{array}{l}\text { f6a - Acumulação } \\
\text { biotopográfica }\end{array}$ \\
\hline$\left|\begin{array}{c}E \\
0 \\
-\infty\end{array}\right|$ & $\frac{5,0 \mathrm{~m}}{4=3}$ & f2 - Antepraia superior & $\begin{array}{c}E \\
\stackrel{5}{-} \\
-\end{array}$ & $5,0 \mathrm{~m}$ & $\begin{array}{l}\text { f6b - Face de } \\
\text { avalanche }\end{array}$ \\
\hline$\underline{E}$ & 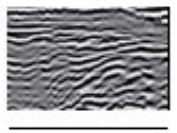 & $\begin{array}{l}\text { f3- Leques de } \\
\text { transposição }\end{array}$ & \multirow[t]{2}{*}{$\begin{array}{c}E \\
5 \\
- \\
\sim\end{array}$} & & \multirow[t]{2}{*}{$\begin{array}{l}\text { f6c - Estratificação } \\
\text { cruzada }\end{array}$} \\
\hline & $10,0 \mathrm{~m}$ & & & $5,0 \mathrm{~m}$ & \\
\hline$\frac{1}{E}$ & $\frac{20 \mathrm{~m}}{20}$ & $\begin{array}{l}\text { f4 - Esporão } \\
\text { lagunar }\end{array}$ & $\begin{array}{c}E \\
5 \\
-\infty\end{array}$ & $\frac{5,0 \mathrm{~m}}{5,5}$ & $\begin{array}{l}\text { f6d - Face de } \\
\text { acreção }\end{array}$ \\
\hline
\end{tabular}

Figura 4 - Legenda das radarfácies utilizadas no presente trabalho. 


\section{Resultados}

\section{Delta do Paraíba do Sul (Gargaú)}

A extensa planície costeira mapeada está ancorada nos tabuleiros terciários do Grupo Barreiras e nos sedimentos fluvio-lagunares, cuja evolução esteve associada às oscilações do nível do mar no Quaternário e as fases de deltação do rio Paraíba do Sul (Figura 5). A feição morfológica mais marcante nesta planície costeira são as cristas de praia, que são depósitos arenosos construídos pelo espraimento das ondas (Figura 6). Estas feições podem sofrer posterior atuação de processos eólicos, podendo formar capeamento eólico ou dunas frontais sobre os depósitos de origem marinha (TAMURA, 2012; HESP et al. 2005; OTVOS, 2000). Sequências de cristas de praia numa planície marcam o processo de progradação, onde cada crista representa uma paleolinha de praia.

\section{COMPLEXO DELTAICO DO RIO PARAÍBA DO SUL (RJ)}

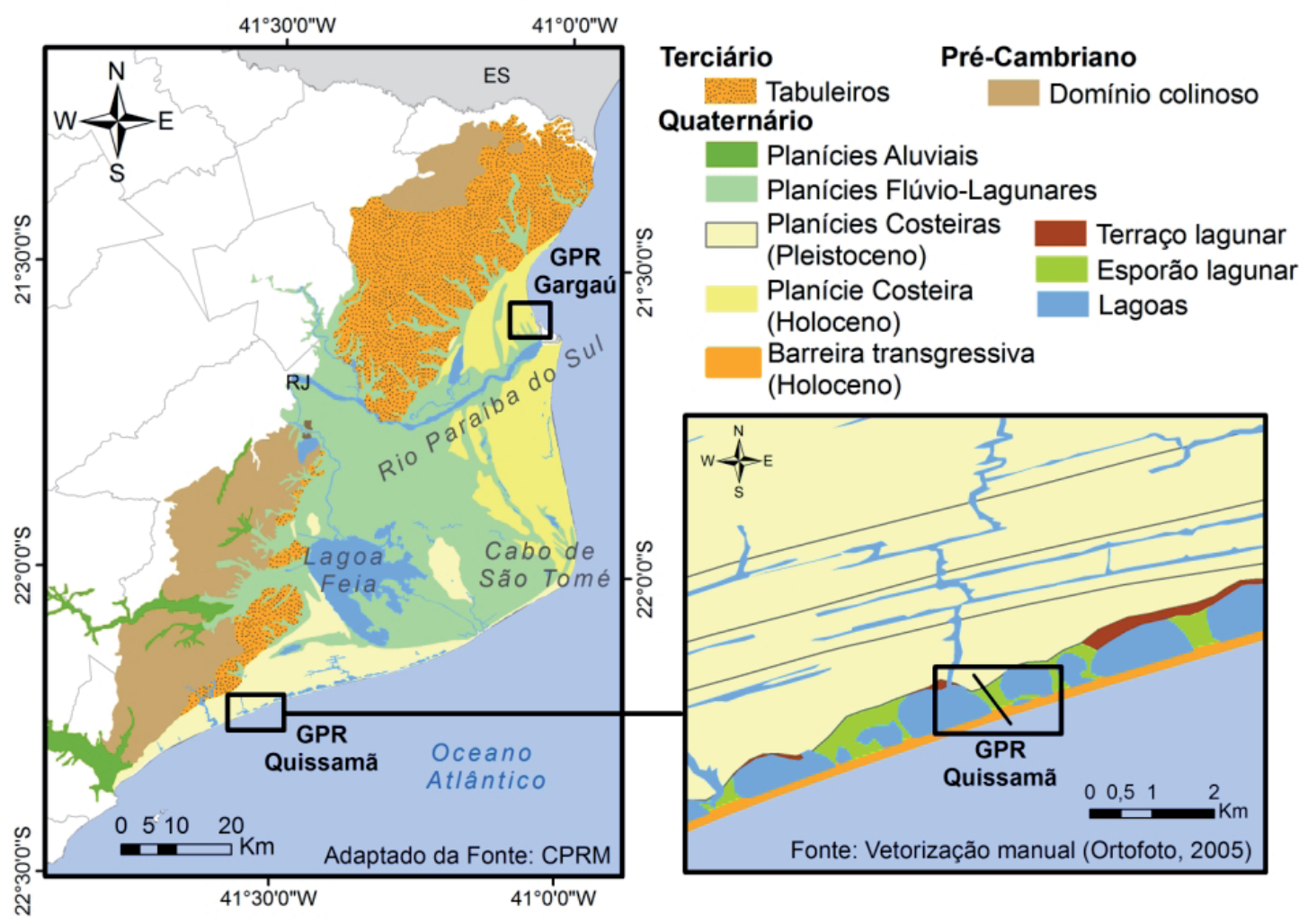

Figura 5 - Mapeamento geomorfológico do complexo deltaico do rio Paraíba do Sul. Destaque para o mapeamento de detalhe em Quissamã.

Na margem norte do delta do Paraíba do Sul esta progradação é bastante evidente no envelope de perfis de praia relativos ao monitoramento entre 2008 e 2014, onde foi identificada uma acreção de cerca de 80 metros em 6 anos (Figura 7), resultando em uma taxa de progradação de aproximadamente 12 m/ano. Esta progradação está diretamente associada ao aporte sedimentar do rio Paraíba do Sul e, em termos evolutivos, às condições de diminuição do nível relativo do mar nos últimos 5.000 anos, que em conjunto propiciaram a formação do delta (Figura 5).
Os mecanismos de incorporação das cristas de praia na margem norte do delta são considerados complexos, conforme descrito por Vasconcelos (2010). Próxima à foz, esta incorporação se dá através da emersão de barras na zona submarina a partir da interação hidrodinâmica fluvial e das ondas. Após a emersão, a barreira isola corpos lagunares efêmeros e migra em direção ao continente pela ação das ondas até ser anexada e as lagunas serem colmatadas. Na área mais afastada da foz e na margem ao sul do rio, essa incorporação se dá pelo espraiamento das ondas na face praial, formando 


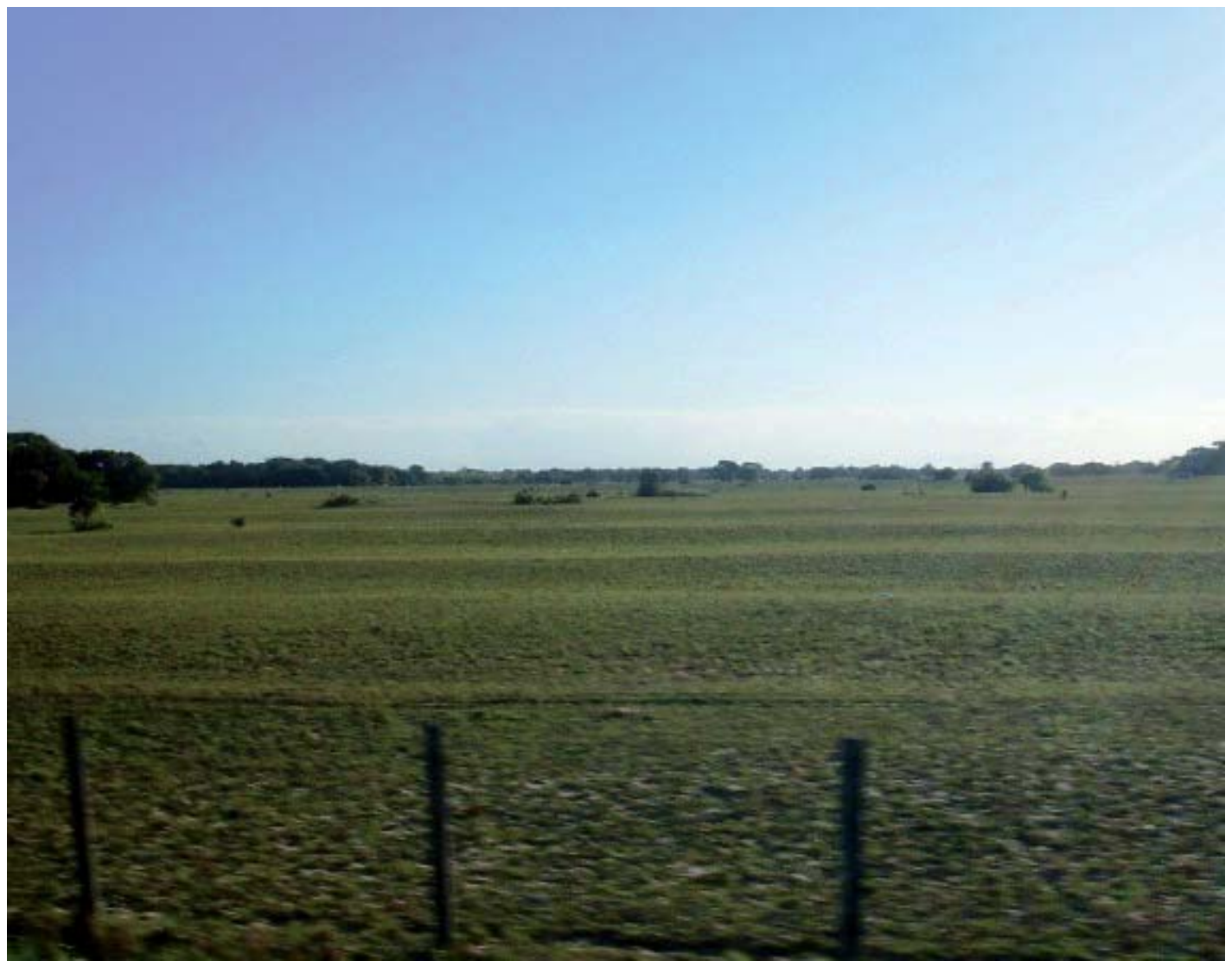

Figura 6 - Morfologia das cristas de praia do delta do rio Paraíba do Sul, no interior da planície. Latitude 21³5’5.67”S, longitude 415’9.36”O.

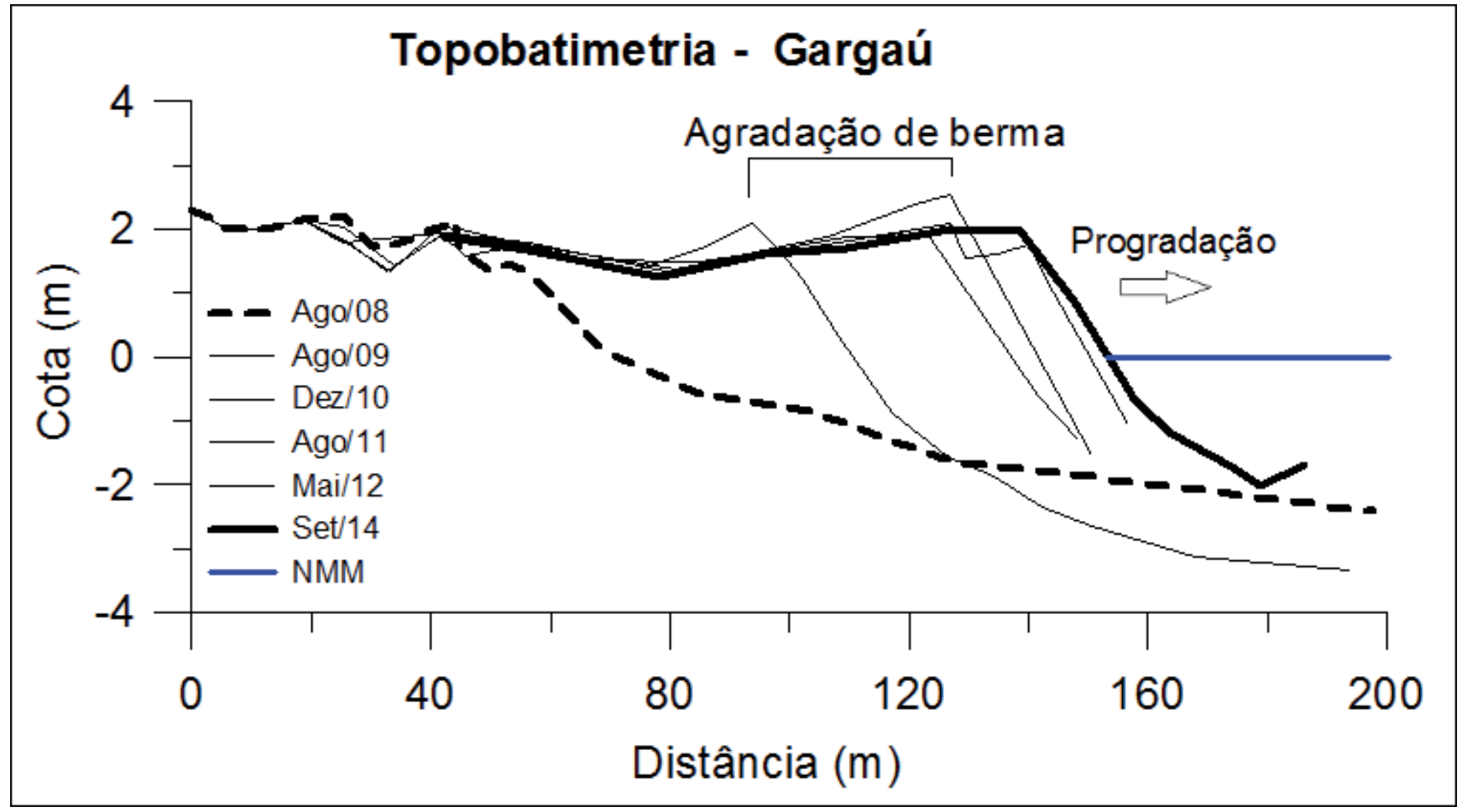

Figura 7 - Monitoramento da linha de costa e morfodinâmica de praia a partir de perfis topobatimétricos em Gargaú. Notar a progradação da barreira costeira. 
bermas, que é considerado o mecanismo mais comum segundo Tamura (2012).

A arquitetura interna é representada pelas radarfácies f1a, f1b e f2, referentes à ambiente praial (Figura 8). A radarfácies f1a apresenta boa continuidade nos refletores. Nesta unidade foi identificada geometria de fácies subparalela a inclinada, com significativo gradiente e mergulho em direção ao mar, indicando respectivamente ambientes deposicionais de pós-praia e zona de estirâncio. Estes refletores indicam uma configuração progradante, apesar da presença de superfícies erosivas, decorrentes de eventos de alta energia. A radarfácies f1b, apesar de estar associado à mesma unidade deposicional da radarfácies anterior, possui configuração distinta, com refletores inclinados em direção ao continente e de média continuidade. Esta radarfácies foi interpre- tada como depósito de agradação de berma, associado ao movimento de espraiamento da onda que alcança o topo do berma. Este reafeiçoamento também pode ser verificado na figura 7.

A radarfácies f2 caracteriza-se por refletores pouco contínuos, de geometria ondulada, com padrão côncavoconvexo, sendo interpretado como de antepraia superior. De acordo com Tamura et al. (2008) este padrão mais complexo está associado à migração de barras na zona submarina. Nesse sentido, a descrição e interpretação destas radarfácies indicam a migração da praia sobre a antepraia, configurando a arquitetura de uma barreira regressiva. A progressiva atenuação do sinal de GPR a partir de -2,0 metros de profundidade pode estar relacionada à presença das lamas de pró-delta conforme mapearam Murillo et al. (2007).

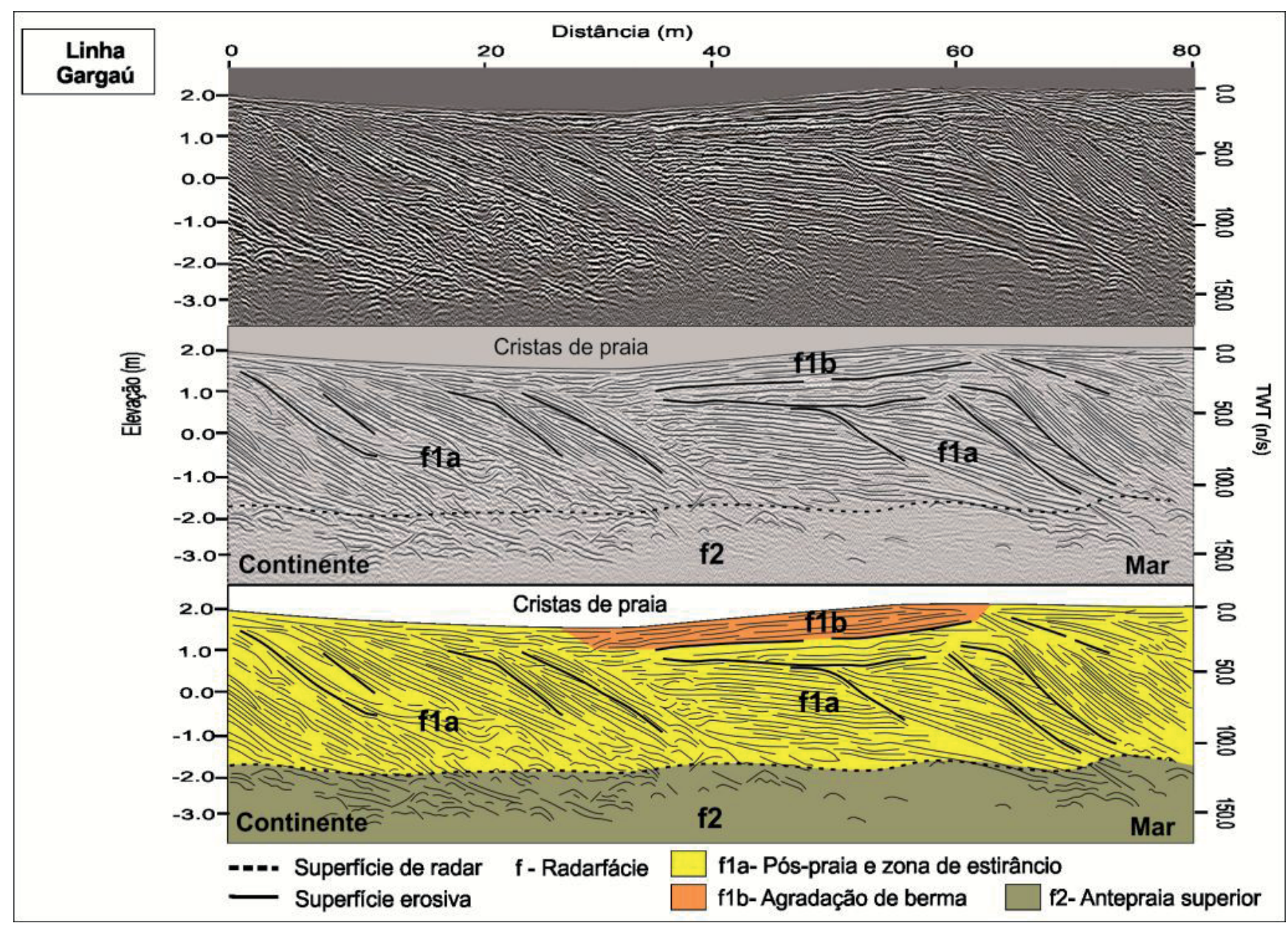

Figura 8 - Seção GPR em Gargaú e as radarfácies interpretadas. Quando comparados aos dados de monitoramento de praia, nota-se a semelhança entre os traços dos perfis monitorados e as estruturas em subsuperfície. 


\section{Litoral de Quissamã}

Assim como a área anterior, o litoral de Quissamã também apresenta uma extensa planície costeira, porém de idade pleistocênica (Figura 5), cuja formação esteve atrelada a uma antiga fase de deltação do rio Paraíba do Sul, quando este provavelmente desaguava próximo ao Cabo de São Tomé (SILVA, 1987; ROCHA, 2013). Essa planície possui as bordas retrabalhadas por lagoas costeiras que tem migrado em direção ao continente e são truncadas pela estreita barreira holocênica (Figura 5). Neste caso, este complexo morfológico pode ser denominado de sistema barreira-laguna (ROCHA et al. 2013b), que tem sido associado ao máximo eustático holocênico de 6 à 5.000 anos A.P. (MARTIN et al. 1997; DIAS e KJEFVE, 2009 e ROCHA, 2013). Uma das hipóteses mais utilizadas para a origem deste tipo de barreira é a submersão de feição pré-existente (afogamento in situ) proposto por Hoyt (1967). De acordo com o modelo, as áreas mais deprimidas no reverso de uma planície seriam afogadas a partir de um aumento do nível do mar, gerando corpos lagunares isolados por uma estreita barreira, que pode migrar em direção ao continente.

Neste litoral, as lagunas são separadas entre si por esporões e possuem o formato truncado pela barreira frontal, indicando forte evidência de retrogradação (Figura 5 e 9). O monitoramento de perfis transversais à linha de costa tem indicado um recuo da escarpa erosiva em torno de 1m/ano (Figura 10), que tem sido corroborado por Quadros et al. (2012), a partir do mapeamento da linha de costa em fotografias aéreas.

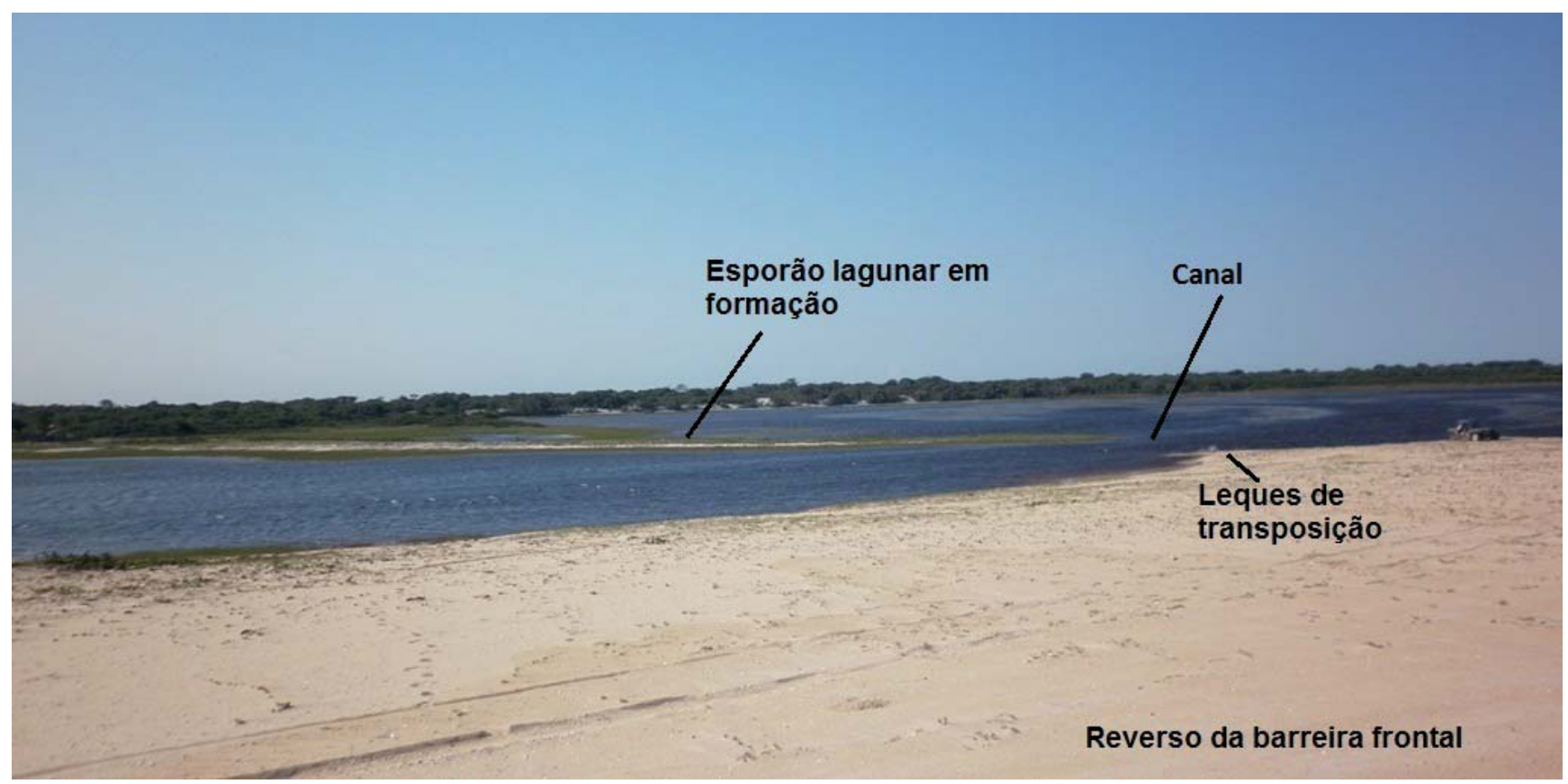

Figura 9 - Exemplo atual de um trecho do litoral de Quissamã, onde a extremidade do esporão está próximo de se conectar à cúspide gerada a partir dos leques de transposição.

Como este litoral está submetido à condições de elevada energia de ondas e frequentes eventos de ressaca (MACHADO, 2007), a retrogradação ocorre a partir dos efeitos de transposição das ondas, que chegam a reafeiçoar o reverso do barreira. Este é considerado um dos principais mecanismos de retrogradação de barreiras costeiras, podendo resultar no afloramento de sedimentos lagunares na face de praia (Figura 11).
O estágio da morfodinâmica de praia é o refletivo, apresentando declividade alta na face de praia, berma elevada, praia composta de areia grossa à muita grossa, sem zona de surfe e submetido à grande energia de ondas. Segundo Calliari et al. (2003), nesta região, as ondas arrebentam de forma mergulhante e se espraiam na face de praia com grande velocidade $(300 \mathrm{~cm} / \mathrm{s})$ e por distâncias que variam entre 10 e 20 metros, facilitando a erosão subaérea da praia. 
Barreiras Costeiras Holocênicas: Geomorfologia e Arquitetura Deposicional no Litoral do Rio de Janeiro

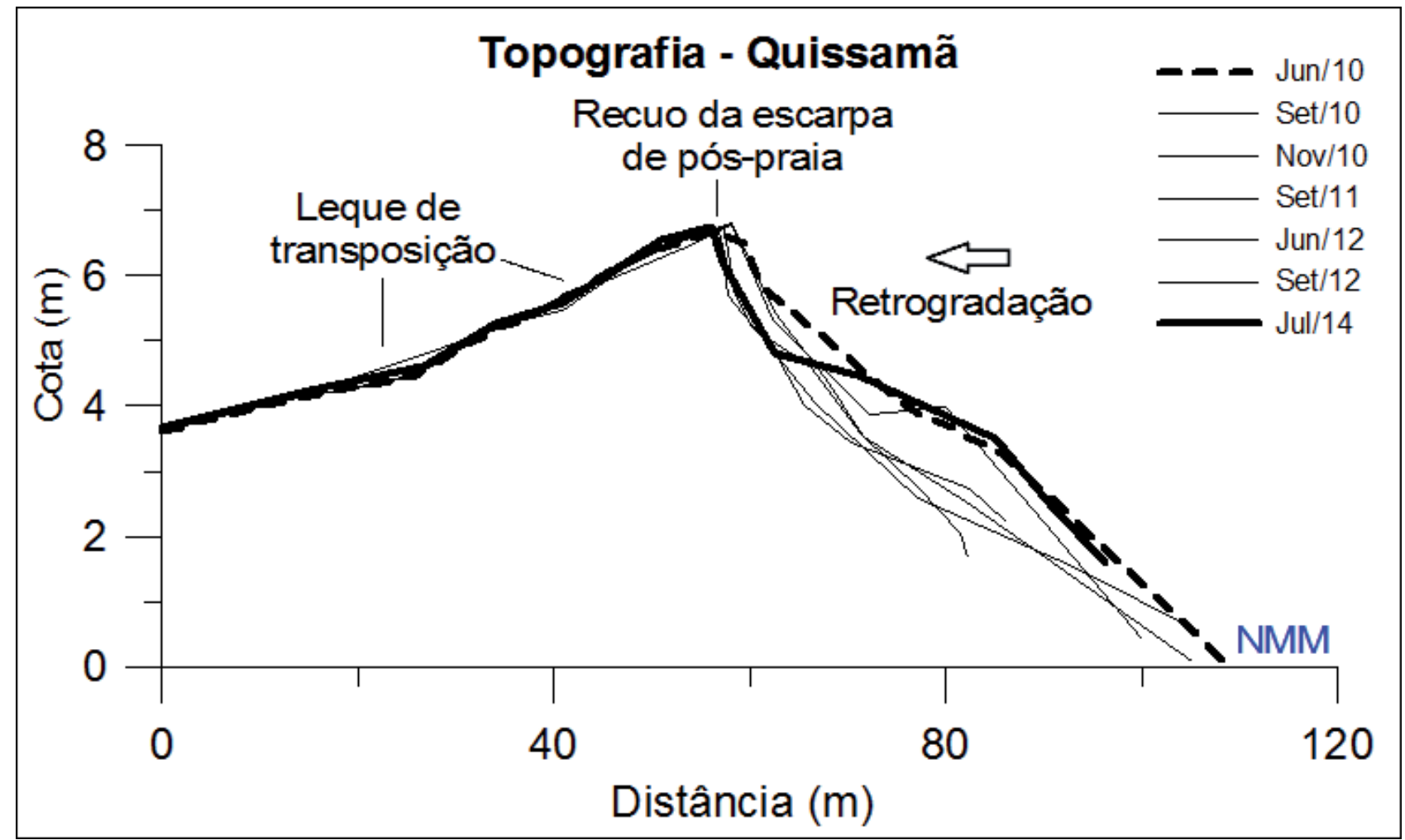

Figura 10 - Monitoramento da linha de costa e morfodinâmica de praia a partir de perfis topográficos em Quissamã. Notar o recuo da escarpa de pós-praia da barreira costeira.

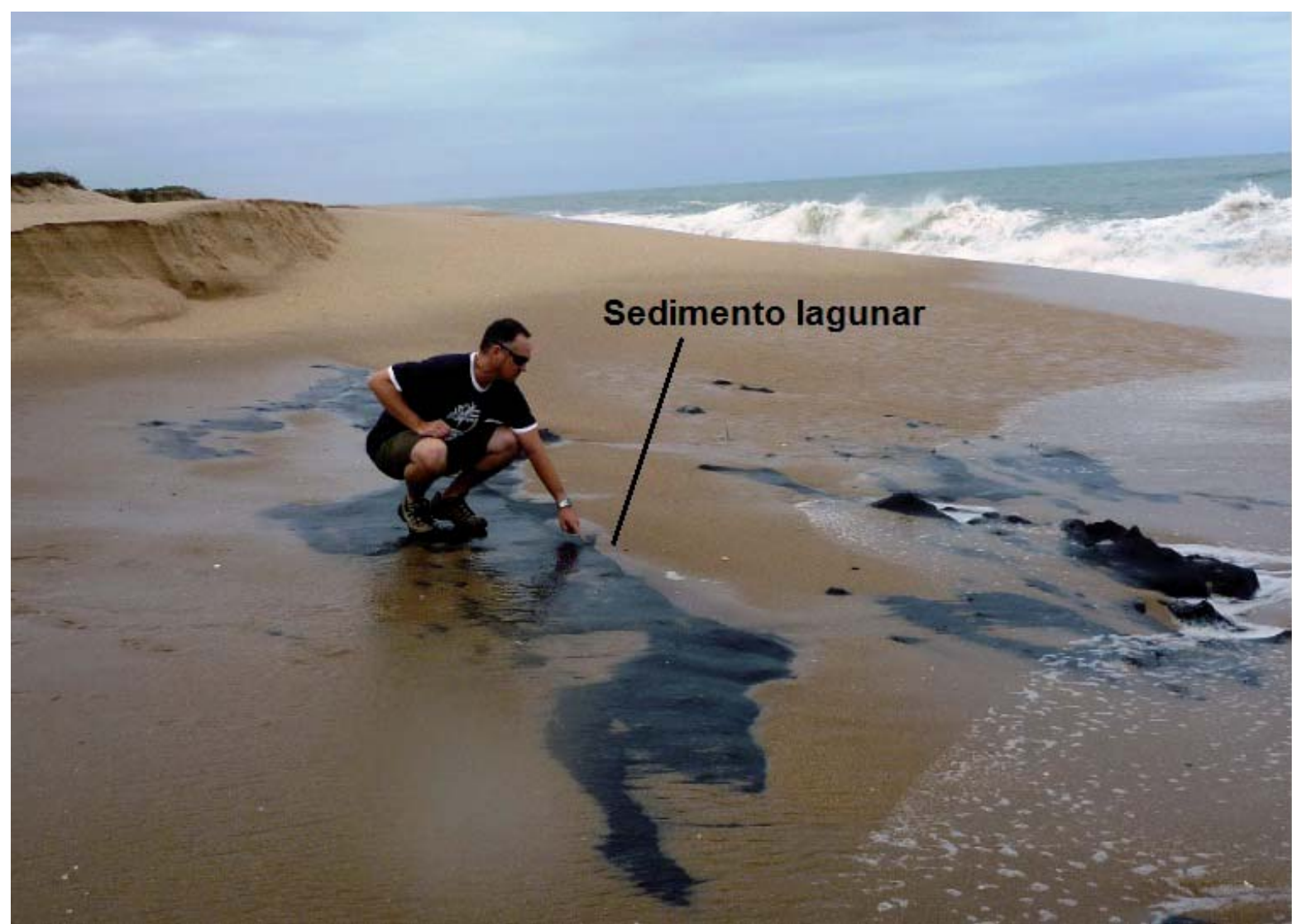

Figura 11 - Sedimentos lagunares aflorando na face de praia (Set/2010). Latitude 22¹6’33.73”'S; Longitude 41³8’36.45”O. 
A arquitetura sedimentar interna revela refletores arenosos associados aos leques de transposição (f3), crescimento de esporão lagunar (f4) e depósito lagunar (f5). A radarfácies $\mathrm{f} 3$ apresenta geometria inclinada e mergulho em direção ao continente (Figura 12). A radarfácies f4 é composta por refletores de média continuidade, elevada inclinação, onde a direção do mergulho aparece em direção ao mar e em direção ao continente. Estes refletores são característicos da migração de um esporão lagunar que se forma a partir do retrabalhamento da planície pleistocênica, presente na borda interna da laguna (Figura 5) e outro esporão que se forma pelo retrabalhamento dos leques de transposição, que estão no reverso da barreira transgressiva. Esta configuração resulta nas direções distintas do mergulho da radarfácies, isto é, em direção ao mar e ao continente respectivamente.

Enquanto os esporões não se conectam e segmen- tam a laguna, forma-se um canal entre eles, conforme mostra um exemplo atual na figura 9. Na seção GPR, há uma série de superfícies erosivas de paleocanais no centro do esporão. Estes são formados pela deposição basal do encontro dos esporões (f4) que migram em direção ao outro. Alterações no volume d'água da lagoa e/ou retrabalhamento do esporão por correntes internas podem criar uma sucessão de eventos erosivos e deposicionais, limitadas por essas superfícies erosivas.

O canal desenvolvido a partir da progradação das radarfácies $\mathrm{f} 4$ tende a ser preenchido pelos leques de transposição representados pela unidade f3 e também pela radarfácie f5 (Figura 12). Esta apresenta reflexão bastante atenuada, sendo interpretada como depósito lagunar. A base do registro também foi interpretada pela radarfácie f5, o que é corroborado pelo afloramento desses depósitos no ambiente praial (Figura 11).

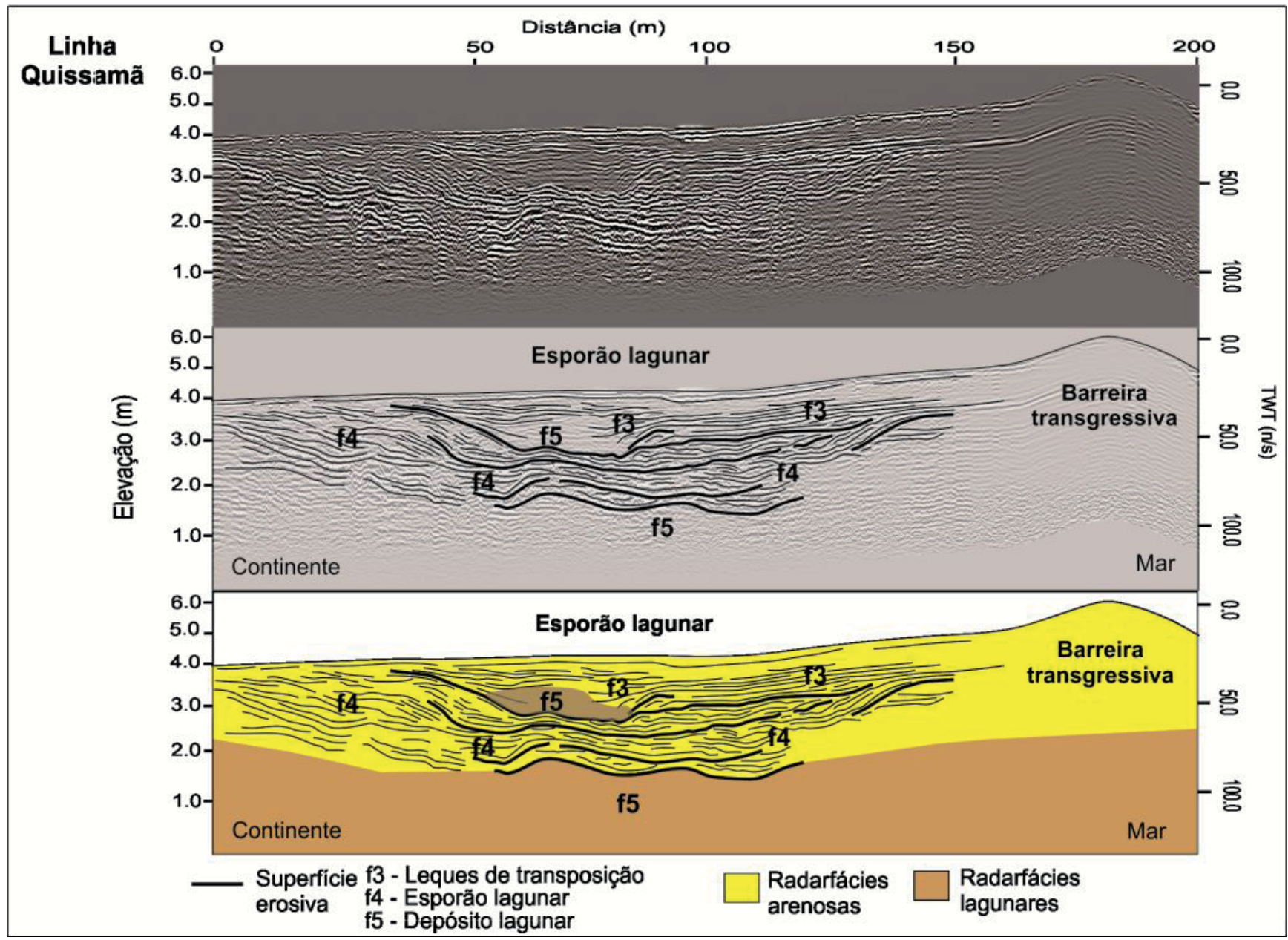

Figura 12 - Seção GPR em Quissamã e as radarfácies interpretadas. Destaca-se que as radarfacies f4 apresentam condições de convergência de transporte sedimentar indicado pela direção dos refletores, além da superposição de refletores associados a transposição. 


\section{Praia do Peró (Cabo Frio)}

A barreira holocênica em Cabo Frio possui a presença de dunas frontais expressivas, que chegam a ultrapassar a cota de 7,0 metros em relação ao nível médio do mar em alguns setores (Figura 13). De acordo com Hesp (2002), as dunas frontais são definidas como estruturas deposicionais paralelas à linha de costa formada no setor de pós-praia por ação eólica, podendo ser embrionárias ou estabilizadas. A zona submarina e a praia apresentam o papel de fonte de sedimentos que depois passam ser remobilizados pelos ventos, criando depósitos estabilizados pela vegetação pioneira.

O desenvolvimento destas feições eólicas na planície do Peró está associado às características climáticas e da morfodinâmica costeira da área (FERNANDEZ et al. 2009). Segundo Barbieri (1984) o litoral compreendido entre Araruama e Cabo Frio possui precipitação anual reduzida, podendo chegar a $800 \mathrm{~mm} / \mathrm{ano}$, representando uma variação do clima Semi-Árido Quente (BSh). Fatores como ressurgência e ausência de controle orográfico explicam esta característica. Outro fator importante é dado pela predominância dos ventos de nordeste associados às condições de tempo bom oriundos da Alta Pressão do Atlântico Sul (BARBIERI, 1984), configurando um padrão de ventos de mar para terra.

Em termos morfodinâmicos as praias possuem características entre o estágio intermediário e dissipativo (FERNANDEZ et al. 2009; PEREIRA et al. 2010) considerados ideais para o desenvolvimento de dunas frontais, devido a granulometria composta por areias finas e berma extensa, que funciona como uma pista para ação dos ventos e a retirada eficiente dos sedimentos mais finos (SHORT e HESP, 1982). Além disso, a zona submarina é considerada a principal fonte sedimentar, devido ao estoque de areias finas, conforme mapeado por Pereira et al. (2008). Estas condições propiciaram não só a formação das dunas frontais, como também a formação de campos de dunas móveis e vegetadas no interior da planície (Figura 14), cujo contexto evolutivo ainda não foi bem investigado.

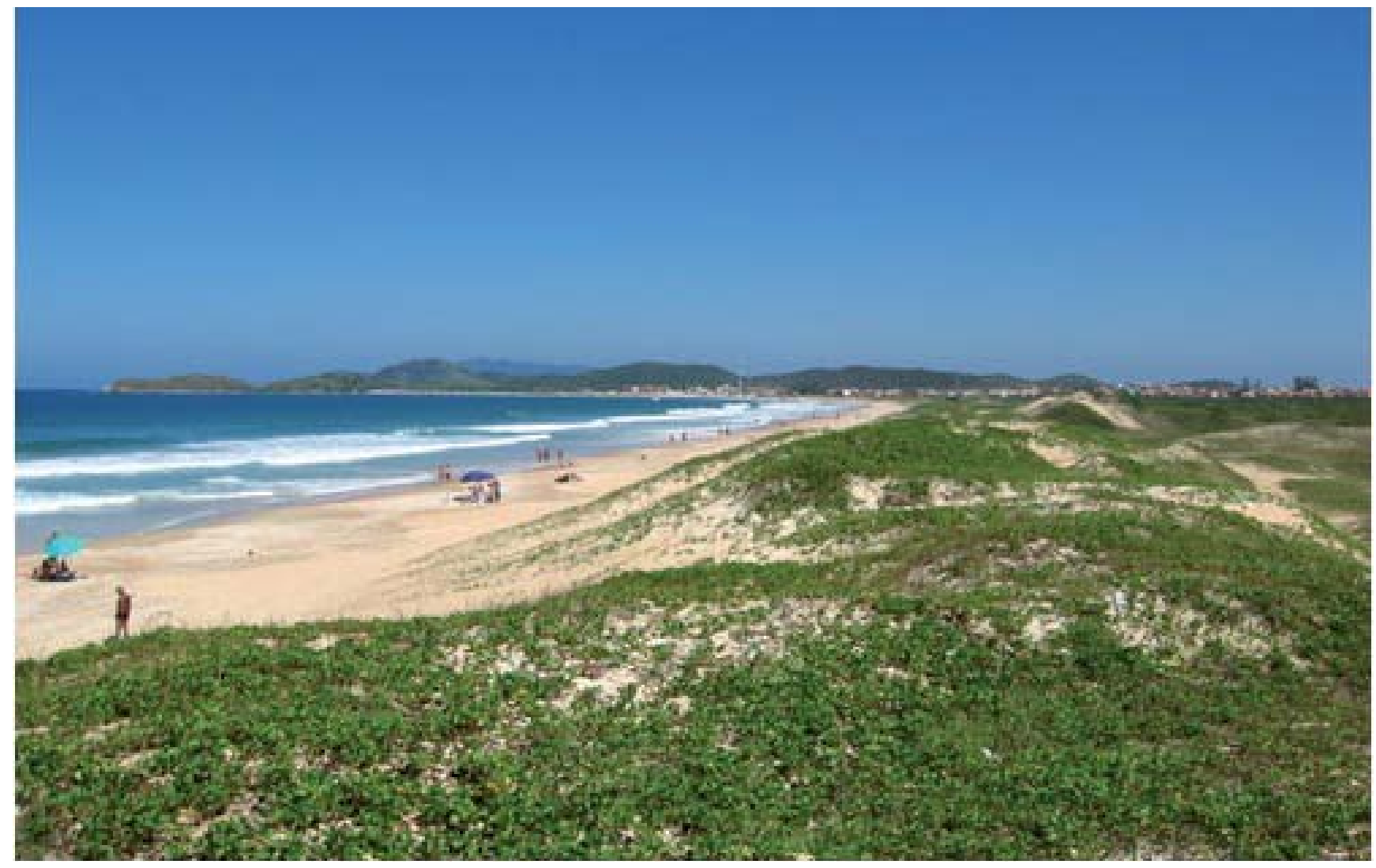

Figura 13 - Dunas frontais bem desenvolvidas na praia do Peró. Latitude 2250’33.63”S; Longitude 4158’59.77”O. 


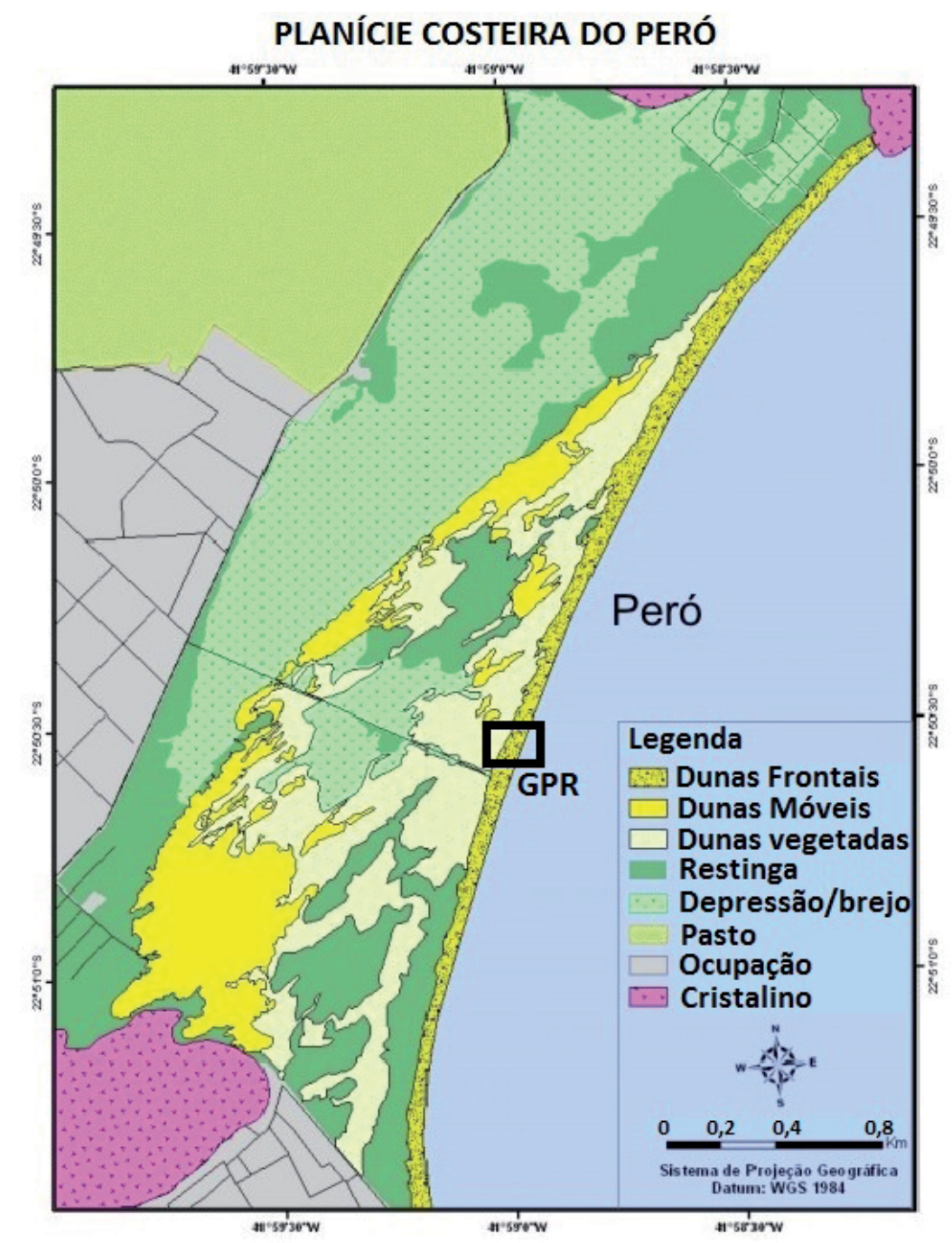

Figura 14 - Mapeamento geomorfológico da planície do Peró.

O envelope de perfis topobatimétricos mostra estabilidade do comportamento da linha de costa, embora eventualmente os eventos de tempestade desenvolvam um perfil erosivo, conforme descrito por Fernandez et al. (2011). O evento de ressaca de abril de 2010 provocou impactos expressivos no litoral centro-norte do Rio de Janeiro. Especificamente a praia do Peró apresentou rápida recuperação e as dunas frontais têm indicado progressivo desenvolvimento (Figura 15).

A arquitetura deposicional reflete uma composição de radarfácies eólicas, representadas por f6a, f6b, f6c e f6d (Figura 16). A radarfácies f6a é caracterizada por refletores de baixa amplitude, baixo ângulo, geometria côncavo-convexo, espessura de $0,5 \mathrm{~m}$ ou menos. A forma convexa é devido à acreção que ocorre ao redor da vegetação fixada na planície de deflação e no topo da duna, enquanto a forma côncava indica pequena erosão ou área reduzida de acumulação Ela é interpretada como acumulação biotopográfica, descrito por Bristow et al.(2000). Abaixo da radarfácies f4a, na planície de deflação, encontram-se refletores que mergulham em direção ao mar e com padrão caótico, cuja interpretação pode ser de depósito praial e/ou brejo. Neste último, ressalta-se a necessidade de informações sedimentológicas para uma interpretação mais criteriosa.

A radarfácies f6b, interpretada como face de avalanche, caracteriza-se por refletores de baixa amplitude, inclinado, alto ângulo e mergulho em direção ao continente. Ela é formada pela deposição na face à sotavento, representando a face de migração da duna. A radarfácies f6c possui média amplitude, mergulho predominante em direção ao continente e refletores sub-horizontais e inclinados que se cruzam. Esta radarfácies foi interpretada como estratificação cruzada que são estruturas comuns em dunas e representam mudanças na direção do agente de transporte.

A radarfácies f6d, interpretada como face de acreção, possui refletores com média continuidade, mergulho 


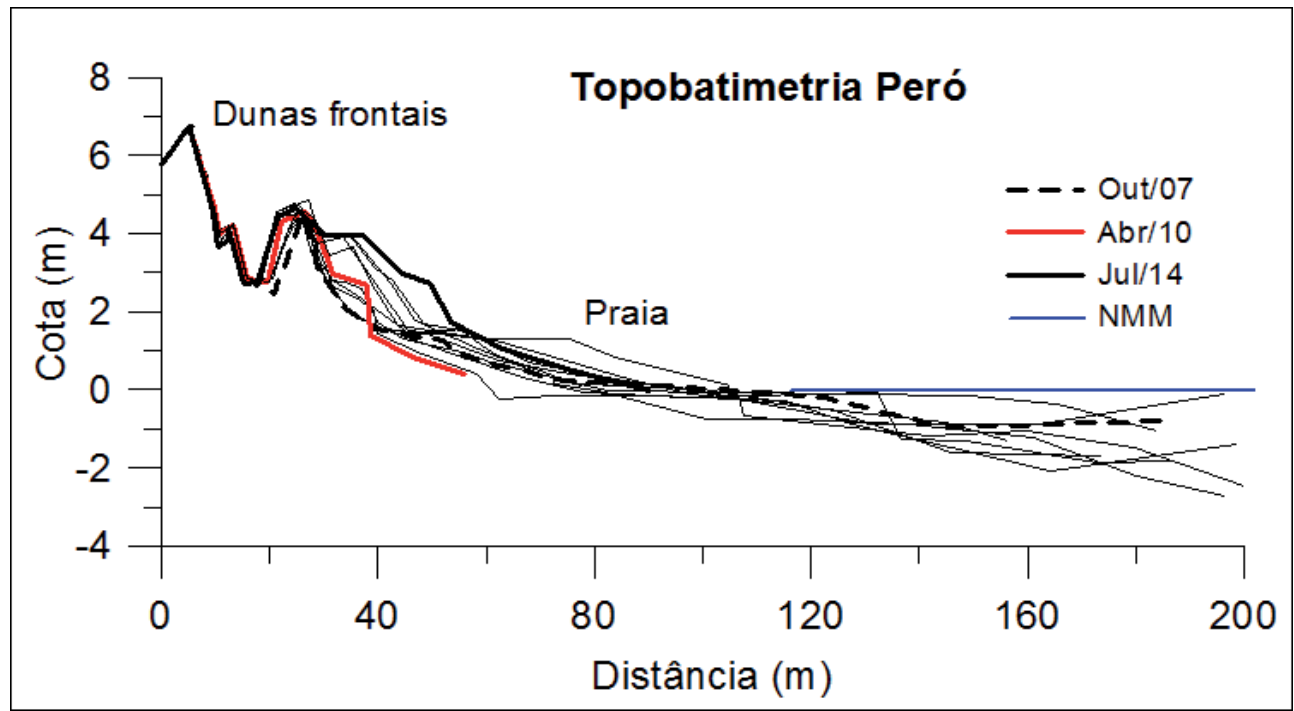

Figura 15 - Monitoramento da linha de costa e morfodinâmica de praia a partir de perfis topobatimétricos no Peró. Notar a recuperação das dunas frontais a partir de abril de 2010.

em direção ao mar, sub-horizontal à levemente inclinado. Refere-se à acumulação sedimentar fixada pela vegetação na face da duna frontal voltada para o mar. À medida que a vegetação se desenvolve em direção à praia ocorre uma acreção deposicional com estratos que mergulham em direção ao mar (BRISTOW et al., 2000).

\section{Discussões}

Esses três exemplos apresentados possuem morfologia e arquitetura deposicional característico dos três principais tipos de barreiras costeiras sistematizados por Kraft e Jonh (1979), Roy et al. (1994),

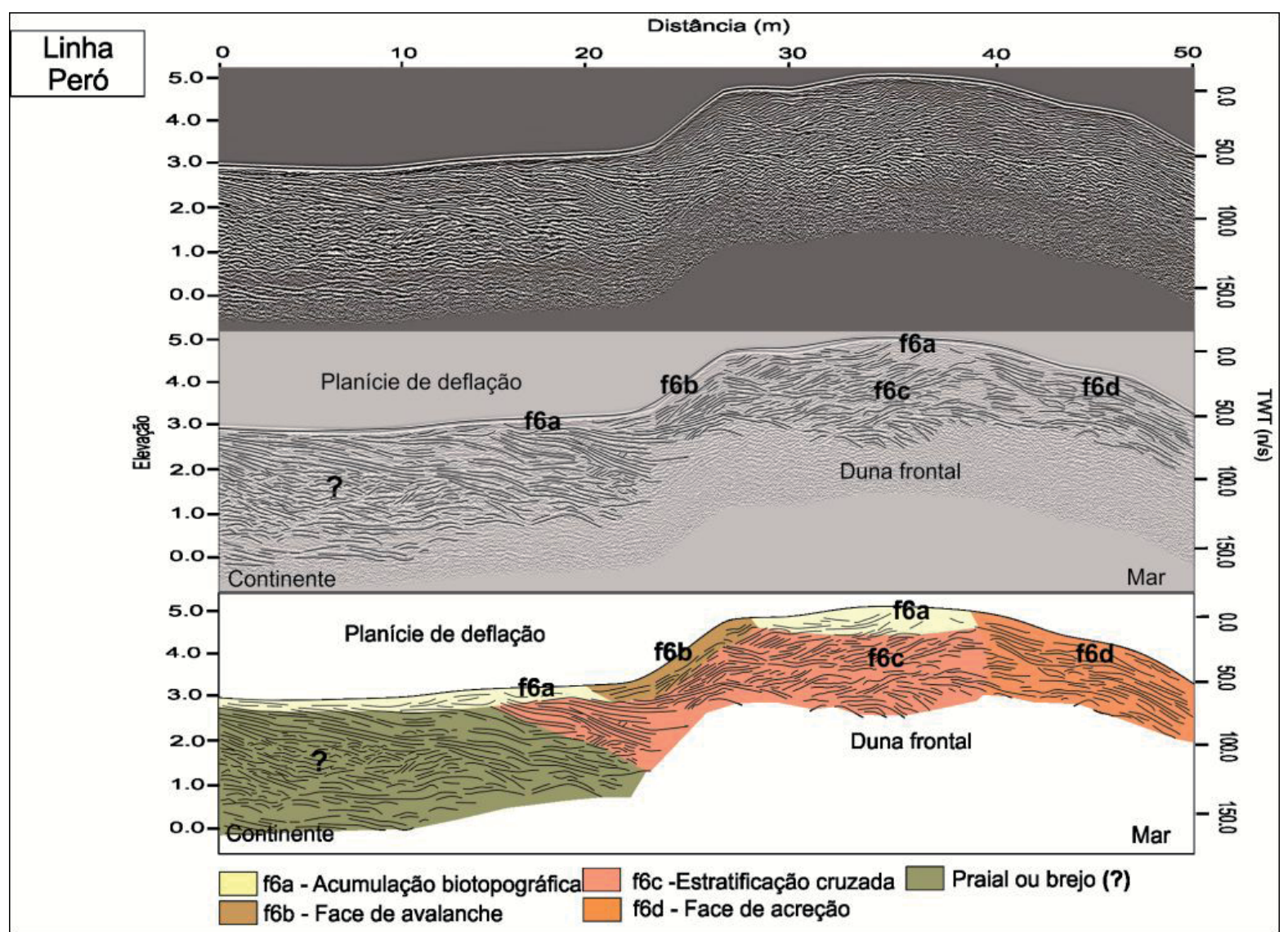

Figura 16 - Seção GPR no Peró e as radarfácies interpretadas. 
Dillenburg e Hesp (2009) e Otvos (2012). Em Gargaú, a morfologia de cristas de praia reflete a migração do ambiente praial sobre a antepraia, compondo uma extensa planície costeira, associado ao aporte fluvial do rio Paraíba do Sul. Em planícies deltaicas, as barreiras regressivas são bastante comuns em função do significativo aporte sedimentar fluvial. Podem apresentar complexos registros estratigráficos, sobretudo em função da tendência que os deltas possuem de sofrer subsidência local e de processos de avulsão e abandono de lobos deltaicos (KRAFT e JOHN, 1979; BHATTACHARYA e GIOSAN, 2003).

Em Quissamã, a morfologia da barreira truncando lagunas costeiras, resultando no afloramento de sedimentos lagunares na praia, evidencia a composição transgressiva também expressa nas radarfácies interpretadas. Além disso, à medida que a barreira retrograda, o corpo lagunar torna-se mais estreito, assumindo uma geometria propícia ao desenvolvimento de esporões, conforme descrito inicialmente por Zenkovitch (1959).

Nesta área, a ausência de aporte sedimentar moderno oriundo do rio Paraíba do Sul, cuja desembocadura teria migrado em direção à Gargaú durante o Holoceno (SILVA, 1987; ROCHA, 2013) pode ter contribuído para o comportamento transgressivo deste setor do litoral. Além disso, a constante exposição a eventos de ressaca também pode ser considerada como causa para a retrogradação da barreira, cujo principal mecanismo envolve ação dos eventos de transposição. Na seção GPR, a radarfácies $\mathrm{f} 3$, associadas aos leques, corrobora a ação deste mecanismo. Forbes et al. (2004) ressalta que as ressacas podem desempenhar um papel semelhante ao aumento do nível do mar em meso-es- cala, pois parte dos sedimentos podem ser direcionados para a plataforma continental e não retornar ao perfil de praia ativo. Embora esta perda não seja significativa numa escala anual, os autores ressaltam a importância quando considerado numa escala de décadas e séculos (NIEDORADA et al. 1985).

No Peró, o modelo agradacional é formado através do empilhamento vertical dos sedimentos em resposta a elevação do nível do mar e condições morfodinâmicas propícias ao retrabalhamento eólico, geralmente refletindo num comportamento de linha de costa estável (ROY et al. 1994). Nesse caso, o estado da morfodinâmica de praia intermediário/dissipativo, possui papel relevante na caracterização da barreira costeira, uma vez que cria condições favoráveis ao desenvolvimento das dunas frontais, atrelado ainda às condições climáticas e a estabilização pela vegetação, conforme identificadas nas radarfácies f6a, f6b, f6c e f6d.

Os diferentes modelos de barreiras costeiras holocênicas apresentados no litoral fluminense revelam que a diminuição do nível relativo do mar durante os últimos 5.000 anos aproximadamente (ANGULO et al. 2006) não foi suficiente para gerar condições regressivas de maneira generalizada, sendo restrita a áreas com aporte fluvial direto, como o caso do delta do rio Paraíba do Sul (Quadro 1). Nesse período, o comportamento da linha de costa e das barreiras costeiras parece ser mais influenciado pelo balanço sedimentar, conforme apontou Dominguez (2011) para o caso da costa leste brasileira, além de fatores como condições morfodinâmicas, potencial eólico e exposição a eventos de ressaca.

Quadro 1: Síntese das características dos exemplos de barreiras costeiras

\begin{tabular}{|c|c|c|c|}
\hline $\begin{array}{c}\text { Barreira } \\
\text { (tipologia) }\end{array}$ & Gargaú & Quissamã & Peró \\
\hline Morfologia & Cristas de praia & Barreira-laguna & Dunas frontais \\
\hline $\begin{array}{c}\text { Comportamento } \\
\text { da linha de } \\
\text { costa }\end{array}$ & Progradação & Retrogradação & Estabilidade \\
\hline $\begin{array}{c}\text { Morfodinâmica } \\
\text { de praia }\end{array}$ & Variável & Refletiva & $\begin{array}{c}\text { Intermediária/ } \\
\text { Dissipativa }\end{array}$ \\
\hline $\begin{array}{c}\text { Aporte fluvial } \\
\text { Radarfácies }\end{array}$ & Rio Paraíba do \\
Sul & fa, f1b e f2 & f3, f4 e f5 & f6a, f6b, f6c e f6d \\
\hline
\end{tabular}




\section{Considerações Finais}

As diferentes características das barreiras costeiras mostradas neste trabalho sugerem que ainda foram pouco exploradas nuances da evolução quaternária das barreiras arenosas costeiras, sobretudo no litoral fluminense. Embora o presente artigo tenha abordado os principais tipos de barreiras costeiras mais utilizadas na literatura da geomorfologia costeira, recentemente outras tipologias têm sido desenvolvidas e investigadas principalmente na costa brasileira e australiana, como as dunas transgressivas, as barreiras anexadas e as barreiras complexas conforme apresentado por Otvos (2012).

Em termos metodológicos o estudo das barreiras costeiras tem avançado a partir da utilização do GPR. Este tem permitido a identificação da arquitetura deposicional, definição das radarfácies e características das unidades deposicionais, de forma não invasiva. Ainda assim, a sua utilização em barreiras costeiras pode apresentar algumas dificuldades para a penetração do sinal de radar devido á proximidade com a salinidade da água do mar e da presença de sedimentos lamosos sob a barreira. Nesse sentido, a resposta do sinal pode variar de lugar para lugar considerando o tipo de material em subsuperfície e suas propriedades elétricas.

A utilização de imagens de alta resolução espacial e métodos geofísicos têm permitido o contínuo avanço na investigação sobre as barreiras costeiras, resultando em novas tipologias, discussões sobre a gênese e os mecanismos que influenciam seu comportamento e evolução, conforme têm apontado McBride et al. (2013) e VanHeteren (2014). Nesse sentido, tais estudos possuem relação direta com as variações do nível do mar na escala geológica e também refletem a necessidade da compreensão de aspectos processuais, como clima de ondas, aporte sedimentar e morfodinâmica costeira. Destas duas abordagens deve-se ainda buscar a necessidade da investigação de mesoescala (histórica) que, segundo French e Burningham (2009), pode gerar a formulação de cenários e o gerenciamento das respostas às perspectivas das mudanças climáticas relacionados aos possíveis cenários de aumento do nível do mar e do aumento da frequência e magnitude das ondas de tempestade.

\section{Referências Bibliográficas}

ANGULO, R. J.; LESSA, G. C.; SOUZA, M. C. A critical review of mid- to late-Holocenesea-level fluctuations on the eastern Brazilian coastline. Quaternary Science Reviews, n.25, p.486-506, 2006.
BANERJEE, D.; HILDEBRAND, A. N.; MURRAY-WALLACE, C. V.; BOURMAN, R. P.; BROOKE, B. P.; BLAIR, M. New quartz SAR-OSL ages from the stranded beach dune sequence in south-east South Australia. Quaternary Science Reviews, n.22, p.1019-1025, 2003.

BARBIERI, E. B. 1984. Cabo frio e Iguaba Grande: dois microclimas distintos a um curto intervalo espacial. In: LACERDA, L. D.; ARAÚJO, D. S. D.; CERQUEIRA, R.; TURQ, B. (eds). Restingas: Origem, Estruturas, Processos. UFF, Niterói, p 3-12, 1984.

BARBOZA, E. G.; DILLENBURG, S. R.; ROSA, M. L. C. C.; TOMAZELLI, L. J.; HESP, P. A. Ground-penetrating radar profiles of two Holocene regressive barriers in southern Brazil. Journal of Coastal Research, v. SI 56, p. 579-583. 2009.

BARBOZA, E. G.; ROSA, M. L. C. C.; HESP, P. A.; DILLENBURG, S. R.; TOMAZELLI, L. J.; AYUP-ZOUAIN, R. N. Evolution of the Holocene Coastal Barrier of Pelotas Basin (Southern Brazil) - a new approach with GPR data. Journal of Coastal Research, v.SI 64, p. 646-650, 2011.

BENNETT, M. R.; CASSIDY, N. J.; PILE, J. Internal structure of a barrier beach as revealed by ground penetrating radar (GPR): Chesil beach, UK. Geomorphology, n.104 (3-4), p. 218-229, 2008.

BHATTACHARYA, J. P.; GIOSAN, L. Wave-influenced deltas: geomorphological implications for facies reconstruction. Sedimentology 50, 187-210, 2003.

BRISTOW, C. S.; CHROSTON, P. N.; BAILEY, S. D. The structure and development of foredunes on a locally prograding coast: insights from Ground-Penetrating Radar surveys, Norfolk, UK. Sedimentology, n.47, p.923-944, 2000.

CALDAS, L. H. O.; OLIVEIRA, J. G.; MEDEIRO, W. E.; KARL STATTEGGER, K.; VITAL, H. Geometry and evolution of Holocene transgressive and regressive barriers on the semi-arid coast of NE Brazil. Geo-Marine Letter, n.26, p.249-263, 2006.

CALLIARI, L. J.; MUEHE, D.; HOEFEL, F. G.; TOLDO, E. Morfodinâmica Praial: uma breve revisão. Revista Brasileira de Oceanografia, n.51, p.63-78, 2003.

COSTAS, S.; FITZGERALD, D. Sedimentary architecture of a spit-end (Salisbury Beach, Massachusetts): The imprints of sealevel rise and inlet dynamics. Marine Geology, n.284, p.203-216, 2011.

DAVIS JR, R. A.; HAYES, M. O. What is a wave-dominated coast? Marine Geology, n.60, p.313-329, 1984.

DIAS, G. T. M.; KJERFVE, B. 2009. Barrier and Beach Ridge Systems of Rio de Janeiro Coast. In: Dillenburg, S.; Hesp, P. (eds.). Geology and Geomorphology of Holocene Coastal Barriers. Heidelberg: Springer Verlag, p. 225-248, 2009. 
DILLENBURG, S. R.; BARBOZA, E. G.; HESP, P. A.; ROSA, M. L. C. C. Ground Penetrating Radar (GPR) and Standard Penetration Test (SPT) records of a regressive barrier in southern Brazil. Journal of Coastal Research, SI 64, p.651-655, 2011.

DILLENBURG, S. R.; HESP, P. Geology and Geomorphology of Holocene Coastal Barriers. Heidelberg: Springer Verlag, v. 107, 2009, 380p.

DOMINGUEZ, J. M. L. A evolução pós-Barreiras da zona costeira leste do Brasil. In: CONGRESSO DA ASSOCIAÇÃO BRASILEIRA DE ESTUDOS DO QUATERNÁRIO ABEQUA, 13., 2011, Armação de Búzios (RJ), Anais... Rio de Janeiro, Associação Brasileira de Estudos do Quaternário, 2011.

FERNANDEZ, G. B.; BULHÕES, E. M. R; ROCHA, T. B. Impacts of Severe Storm Occurred in April 2010 along Rio de Janeiro Coast, Brazil. Journal of Coastal Research, SI 64, 1850-1854, 2011.

FERNANDEZ, G. B.; PEREIRA, T. G.; ROCHA, T. B. Coastal Dunes Along Rio de Janeiro Coast: Evolution and Management. Journal of Coastal Research, SI 56, 307-311, 2009.

FERNANDEZ, G. B.; ROCHA, T.B; MALUF, V.; BULHÕES, E.M.R. Características morfodinâmicas das praias do litoral centro-norte do estado do Rio de Janeiro. In: SIMPÓSIO NACIONAL DE GEOMORFOLOGIA, 9, 2012, Rio de Janeiro (RJ), Anais... p. 1-5, 2012.

FORBES, D. L.; PARKES, G. S.; GALVIN, K. M.; KETCH, L. A. Storms and shoreline retreat in the southern Gulf of St. Lawrence. Marine Geology, n. 210, p.169-204, 2004.

FRENCH, J. R.; BURNINGHAM, H. Coastal Geomorphology: trends and challenges. Progress in Physical Geography, 33(1), p.117-129, 2009.

GALLOWAY W.E.; HOBDAY D.K. Terrigenous Clastic Depositional Systems. Springer-Verlag. New York. 1983, 423p.

GIRARDI, J.; DAVIS, D. M. 2010. Parabolic dune reactivation and migration at Napeague, NY, USA: Insights from aerial and GPR imagery. Geomorphology, n.114, p.530-541, 2010.

HESP, P. Foredunes and blowouts: initiation, geomorphology and dynamics. Geomorphology, v.48, 245 - 268, 2002.

HESP, P. A.; DILLENBURG, S. R.; BARBOZA, E. G.; TOMAZELLI, L. J.; AYUP-ZOUAIN, R. N.; ESTEVES, L. S.; GRUBER, N. S.; TOLDO-JR, E. E.; TABAJARA, L. L. C; CLEROT, L. C. P. Beach ridges, foredunes or transgressive dunefields? Definitions and an examination of the Torres to Tramandaí barrier system, Southern Brazil. Anais da Academia Brasileira de Ciências, 77 (3), p.493-508, 2005.

HOYT, J. H. Barrier Island Formation. Geological Society of America Bulletin, n.78, p.1125-1136, 1967.
KRAFT, J. C.; JOHN, C. J. Lateral and vertical facies relations of transgressive barrier. American Association of Petroleum Geologists Bulletin, n.63, p.2145-2163, 1979.

MACHADO, G. M. V. Análise morfo-sedimentar da praia, antepraia e plataforma continental interna da linha de costa do Parque Nacional de Jurubatiba- RJ. (Dissertação de mestrado em geografia) Universidade Federal do Rio de Janeiro, Rio de Janeiro. 177p. 2007.

MARTIN, L.; SUGUIO, K.; DOMINGUEZ, J. M. L.; FLEXOR, J. M. Geologia do Quaternário costeiro do litoral norte do Rio de janeiro e do Espírito Santo. CPRM Serviço Geológico do Brasil. 1997, 112p.

McBRIDE, R. A.; ANDERSON, J. B.; BUYNEVITCH, I. V.; CLEARY, W. FENSTER, M. S.; FITZGERALD, D. M.; HARIS, M. S.; HEIN, C. J.; KLEIN, A. H. F.; LUI, B.; DE MENSES, J. T.; PEJRUP, M.; RIGS; S. R.; SHORT, A. D.; STONE, G. W.; WALLACE, D. J.; WANG, P. Morphodynamics of Barrier Systems: a synthesis. In: Shroder, J. (Ed) Treatise of Geomorphology. Associated Press. 2013.

MUEHE, D.; VALENTINI, E. Litoral do Estado do Rio de Janeiro - Uma Caracterização Físico-Ambiental. Fundação de Estudos do Mar (FEMAR). 1998, v.1. 93p.

MURILLO, V. C.; SILVA,C. G.; FERNANDEZ, G. B. Discussão sobre a contribuição dos sedimentos da plataforma continental interna para formação da planície de cristas de praia do delta do Rio Paraíba do Sul. In: XI CONGRESSO DA ABEQUA, Bélem (PA). Anais...Belém (PA) 2007.

NEAL, A. Ground-penetrating radar and its use in sedimentology: principles, problems and progress. Earth-Science Reviews, n.66, p.261-330, 2004.

NIEDORODA, A. W., SWIFT, D. J. P., HOPKINS T. S. The Shoreface. In: DAVIS, R.A. (ed). Coastal Sedimentary Environments. Springer-Verlag. 1985, 716 p.

NIELSEN, A.; MURRAY, A. S.; PEJRUP, M.; ELBERLING, B. Optically stimulated luminescence dating of a Holocene beach ridge plain in Northern Jutland, Denmark. Quaternary Geochronology, v.1, p.305-312, 2006.

NILSEN, L.; MOLLER, I.; NIELSEN, L. H.; JOHANNESSEN, P. N.; PEJRUP, M.; ANDEERSEN, T. J.; KORSHOJ, J. S. 2009. Integrating ground-penetrating radar and borehole data from a Wadden Sea barrier island. Journal of Applied Geophysics, n.68, p.47-59.

OTVOS, E. G. Coastal barriers - Nomenclature, processes and classification issues. Geomorphology, n.139-140, p.39-52, 2012.

OTVOS, E. G. Beach ridges - definitions and significance. Geomorphology, n.32, p.83-108, 2000. 
PEREIRA, T. G.; OLIVEIRA FILHO, S. R., CORREA, W. B., FERNANDEZ, G. B. Diversidade Dunar entre Cabo Frio e o Cabo Búzios - RJ. Revista de Geografia (Recife), v.3, p.250 - 263, 2010

PEREIRA, T. G.; ROCHA, T. B.; FERNANDEZ, G. B. Geomorfologia e Morfodinâmica Costeira da Planície entre Cabo Frio e Arraial do Cabo - RJ. In: SIMPÓSIO NACIONAL DE GEOMORFOLOGIA I ENCONTRO LATINO-AMERICANO DE GEOMORFOLOGIA, 7., 2008 Belo Horizonte (MG). Anais... Belo Horizonte, UFMG, 2008.

PINHO, U. F. Caracterização do estado do mar na Bacia de Campos. (Dissertação de Mestrado). COPPE, Universidade Federal do Rio de Janeiro, Rio de Janeiro. 145p. 2003.

QUADROS, M. A. R.; ROCHA, T. B.; FIGUEIREDO, M. S.; FERNANDEZ, G. B. 2012. Avaliação multitemporal do comportamento da linha de costa no litoral entre Carapebus e Quissamã, RJ - Aplicações com geotecnologias e radar de penetração de solo (GPR). In: SIMPÓSIO NACIONAL DE GEOMORFOLOGIA, 9., 2012, Rio de Janeiro (RJ). Anais... Rio de Janeiro, UFRJ. 2012.

ROCHA, T. B. A planície costeira meridional do complexo deltáico do rio Paraíba do Sul (RJ): arquitetura deposicional e evolução da paisagem durante o Quaternário Tardio. (Tese de doutorado). Instituto Geociências, Universidade Federal do Rio de Janeiro, Rio de Janeiro. 178p. 2013.

ROCHA, T. B; FERNANDEZ G. B.; PEIXOTO, M. N. O; RODRIGUEZ, A. Arquitetura deposicional e datação absoluta das cristas de praia pleistocênicas no complexo deltaico do Paraíba do Sul (RJ). Brazilian Journal of Geology, 43 (4), 711-724, $2013 a$.

ROCHA T. B.; FERNANDEZ G. B. E PEIXOTO M. N. O. Applications of ground-penetrating radar to investigate the Quaternary evolution of the south part of the Paraiba do Sul river delta (Rio de Janeiro, Brazil). Journal of Coastal Research, SI.65, p.570-575, 2013b.

ROY, P. S.; COWELL, P. J.; FERLAND, M.A.;THOM, B. G. Wavedominated coasts. In: CARTER, R.W.G.; WOODROFFE, C.D. (eds.). Coastal evolution: late quaternary morphodynamics. Cambridge University Press, p.121-186, 1994.

SHORT, A. D.; HESP, P. A. Wave, beach and dune interactions in southeast Australia. Marine Geology. v.48, 259 - 284, 1982.

SILVA, A. L. C.; SILVA, M. A. M.; GAMBOA, L. A. P.; RODRIGUES, A. R. Arquitetura sedimentar e evolução deposicional no Quaternário da planície costeira de Maricá, Rio de Janeiro, Brasil. Brazilian Journal of Geology. 44(2): 191206, June 2014.

SILVA, C. G. 1987. Estudo da evolução geológica e geomorfológica da região da Lagoa Feia, RJ. 116 f. Dissertação (Mestrado em Geologia). Instituto Geociências, Universidade Federal do Rio de Janeiro, Rio de Janeiro.

TAMURA, T. Beach ridges and prograded beach deposits as palaeoenvironment records. Earth-Science Reviews, n.114, p. 279-297, 2012.

TAMURA, T.; MURAKAMI, F.; NANAYAMA, F.; WATANABE, W.; SAITO, Y. Ground-penetrating radar profiles of Holocene raised-beach deposits in the Kujukuri strand plain, Pacific coast of eastern Japan. Marine Geology, n.248, p.11-27, 2008.

VAN HETEREN, S. Barrier System. In: Masselink G. e Gehrels, R. (Eds). Coastal Environments and Global Change. AGU e Wiley. 2014.

VASCONCELOS, S. C. Evolução morfológica das barreiras arenosas ao norte da desembocadura do Rio Paraíba do Sul, RJ. (Dissertação de mestrado). Instituto Geociências, Universidade Federal Fluminense, Niterói (RJ). 2010.

WANG, P.; HORWITZE, M. H. Erosional and depositional characteristics of regional overwash deposits caused by multiple hurricanes. Sedimentology, n.54, p.545-564, 2007.

ZENKOVITCH, V. P. On the Genesis of Cuspate Spits along Lagoon Shores. The Journal of Geology, v.67, n.3 (May), p.269-277, 1959. 